\title{
Role of Intracellular Calcium Handling in Force-Interval Relationships of Human Ventricular Myocardium
}

Judith K. Gwathmey, Mara T. Slawsky, Roger J. Hajjar, G. Maurice Briggs, and James P. Morgan

Charles A. Dana Research Institute and the Harvard-Thorndike Laboratory of Beth Israel Hospital, and Cardiovascular Division,

Department of Medicine, Beth Israel Hospital and Harvard Medical School, Boston, Massachusetts 02215

\begin{abstract}
Experiments were performed in human working myocardium to investigate the relationship of intracellular calcium handling and availability to alterations in the strength of contraction produced by changes in stimulation rate and pattern. Both control and myopathic muscles exhibited potentiation of peak isometric force during the postextrasystolic contraction which was associated with an increase in the peak intracellular calcium transient. Frequency-related force potentiation was attenuated in myopathic muscles compared to controls. This occurred despite an increase in resting intracellular calcium and in the peak amplitude of the calcium transient as detected with aequorin. Therefore, abnormalities in contractile function of myopathic muscles during frequency-related force potentiation are not due to decreased availability of intracellular calcium, but more likely reflect differences in myofibrillar calcium responsiveness. Sarcolemmal calcium influx may also contribute to frequency-related changes in contractile force in myopathic muscles as suggested by a decrease in action potential duration with increasing stimulation frequency which is associated with fluctuations in peak calcium transient amplitude. (J. Clin. Invest. 1990. 85:1599-1613.) frequency • postextrasystolic potentiation • action potentials $\bullet$ tetanization $\bullet$ oscillation
\end{abstract}

\section{Introduction}

Over 118 years ago, Bowditch (1) first called attention to the influence of the interval between contractions on the strength of myocardial contraction. Nevertheless, confusion remains regarding the mechanisms underlying the force-interval relationship of working myocardiuin. Conflicts have arisen because of attempts to generalize from observations made in a single species or with muscle taken from different areas of the heart. Seemingly contradictory results have been obtained under experimental conditions that differed with respect to temperature, ionic environment, and level of oxygenation (2).

Portions of this work have previously been published in abstract form: Slawsky et al. 1989. J. Am. Coll. Cardiol. 13:185A; Gwathmey et al. 1987. J. Am. Coll. Cardiol. 9:172A; Gwathmey et al. 1986. Circulation. 74:290.

Dr. Hajjar's present address is Division of Health Sciences and Technology, Harvard-Massachusetts Institute of Technology, Cambridge, MA 02139.

Address reprint requests to Dr. Gwathmey, Cardiovascular Division, Beth Israel Hospital, 330 Brookline Avenue, Boston, MA 02215.

Received for publication 15 August 1989 and in revised form 7 November 1989.

J. Clin. Invest.

(c) The American Society for Clinical Investigation, Inc.

$0021-9738 / 90 / 05 / 1599 / 15 \quad \$ 2.00$

Volume 85, May 1990, 1599-1613
Interval-dependent changes in the strength and time course of contraction result both from alterations in the duration of the active state and from changes in the degree of activation of the contractile elements (e.g., shifts of the force-velocity curve) (2).

The relationship between myocardial contractile force and increased stimulation frequency is positive in many mammalian species but negative in the rat (3). Orchard and Lakatta (3) have suggested that the negative force-frequency relationship in the rat is due to diminished sarcoplasmic reticulum calcium release. Penefsky and colleagues $(4,5)$ also described a negative force-frequency relationship in hypertrophied human myocardium. In addition, hemodynamic studies in patients with heart failure have shown little or no increase in contractility with increasing frequency of stimulation (6). Although it has been proposed that the negative force-frequency relationship in diseased human myocardium does not occur as a result of diminished sarcoplasmic reticulum calcium release $(4,5)$, force-frequency relationships and postextrasystolic potentiation in human myocardium have not previously been studied in relation to calcium handling events. It was therefore of interest to us to investigate the force-frequency relationship and postextrasystolic potentiation in normal and diseased human myocardium in which sarcoplasmic reticulum calcium handling is impaired $(7,8)$. We used aequorin, a bioluminescent indicator, to study intracellular calcium $\left(\left[\mathrm{Ca}^{2+}\right]_{\mathrm{i}}\right)$ handling. Further, we studied action potential parameters and their relationship to excitation-contraction coupling.

Since the terminology in this area of investigation has become increasingly confusing and we recognize the need for uniformity in presentation, we have used the terminology adopted by Wier (9) and Wier and Yue (10).

\section{Methods}

\section{Tissue preparation}

Informed consent was obtained from all recipients and from families of all donors before heart transplantation or excision. Hearts obtained from organ donors without cardiac disease that were not suitable for transplantation were used as controls $(n=18)$. Cardiac tissue was also obtained from patients with end-stage heart failure at the time of cardiac transplantation $(n=20) .14$ of 20 muscles were obtained from patients with idiopathic dilated cardiomyopathy, 5 muscles were obtained from patients with ischemic cardiomyopathy, and 1 from a patient with hypertrophic cardiomyopathy.

At the time of excision, the hearts were placed in an oxygenated physiologic salt solution at room temperature and rapidly transported to the laboratory where a trabecula was dissected free and superfused in oxygenated physiologic salt solution inside a light-collecting apparatus, as previously described (7). 16 of 18 control muscles and 18 of 20 myopathic muscles were from the right ventricle. For control and myopathic muscles, mean fiber diameters were $0.92 \pm 0.08$ and $1.0 \pm 0.12 \mathrm{~mm}$; and mean lengths $8.9 \pm 0.6$ and $9.0 \pm 0.6 \mathrm{~mm}$, respectively. 
Muscles were stretched to $L_{\max }$ and stimulated to contract at frequencies between 0.01 and $2 \mathrm{~Hz}$, with square wave pulses of $5-\mathrm{ms}$ duration at threshold voltage. Punctate stimulation via a platinum electrode at the muscle base was used to minimize catecholamine release from the sympathetic nerve endings (11). Cross-sectional area was estimated on the basis of weight, assuming the muscle to be cylinder with a specific gravity of one. All measurements were made after steady state for a particular pattern of stimulation had been reached.

Cardiac muscles were loaded with aequorin as previously described (12). The light emitted by aequorin was detected with a photomultiplier tube (9635 QA, Thorn EMI, Gencom Inc., Fairfield, NJ). Light signals are reported in amperes of anodal current or as quantitative intracellular calcium concentrations.

The aequorin light signal was calibrated in terms of absolute calcium by the fractional luminescence method of Allen and Blinks (13). Fractional luminescence was then converted to intracellular calcium by use of the appropriate in vitro calibration curve (14).

The peak amplitude of the aequorin signal and peak isometric tension were measured. The time courses of light and tension responses were measured as previously described (7).

Myocyte fiber diameter was measured using a linear ocular grid at a magnification of 400 . The measurement was made in longitudinally sectioned fibers at the level of a centrally located nucleus. 10 fibers per trabecula were measured to obtain a mean myocyte diameter.

\section{Electrophysiology}

Trabeculae carneae used for electrophysiological studies were obtained from the same hearts and handled in a similar fashion as the aequorin-loaded preparations. Action potentials were recorded as previously described (15).

\section{Monoexponential curve-fitting procedure}

Monoexponential functions were fitted to two types of curves (restitution curves and postextrasystolic potentiation curves). A double-exponential function was fitted to frequency potentiation curves (see Results). The Taylor series method of nonlinear least-squared error estimation was used (16). Time constants and $y$-intercepts associated with the fitted exponential functions were determined.

\section{Cellular calcium fluctuations}

Analog records were digitized at $250 \mathrm{~Hz}$. Peak amplitudes were plotted against stimulus number and analyzed with a discrete Fourier transform. Calcium and tension responses in the presence of $2.5 \mathrm{mM}$ $\left[\mathrm{Ca}^{2+}\right]_{0}$ were analyzed at $0.33-$ and $1-\mathrm{Hz}$ stimulation frequencies (17).

\section{Experimental protocols}

Frequency and postextrasystolic potentiation. For postextrasystolic potentiation studies, muscles were allowed to reach steady state at a stimulation frequency of $0.2 \mathrm{~Hz}$ to produce a "conditioned beat." The experimental paradigm is illustrated in Fig. 1. Using the experimental protocol of paired stimulation, a premature stimulus was inserted at $0.25-2 \mathrm{~Hz}$ after the conditioned stimulus ( $C$ in Fig. 1). This premature stimulus produced an extrasystole (E.S. in Fig. 1). The time between the conditioned and premature stimulus was called the extrasystolic interval (E.s.i. in Fig. 1). The time between the premature stimulus and the following potentiated contraction was termed the postextrasystolic interval (P.e.s.i.) and was kept constant at $0.2 \mathrm{~Hz}$ (Fig. 1). In some experiments, a single extrasystole was inserted at random intervals and individual calcium and tension responses were recorded on a beat-tobeat basis.

CONDITIONING INTERVAL

\begin{tabular}{|c|c|c|c|}
\hline 53 & 53 & E.s.i. & P.e.s.i. \\
\hline & & - VARIABLE $\rightarrow$ & - FIXED $5 \mathrm{~s} \rightarrow$ \\
\hline
\end{tabular}

\section{CONTROL MUSCLE}

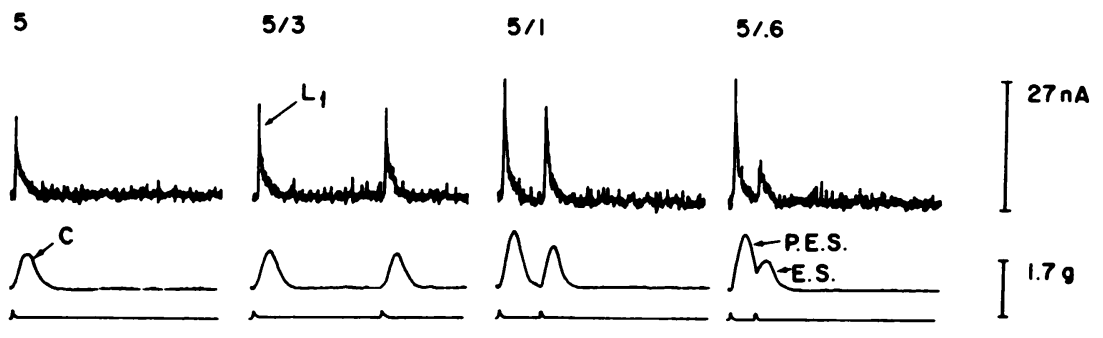

MYOPATHIC MUSCLE

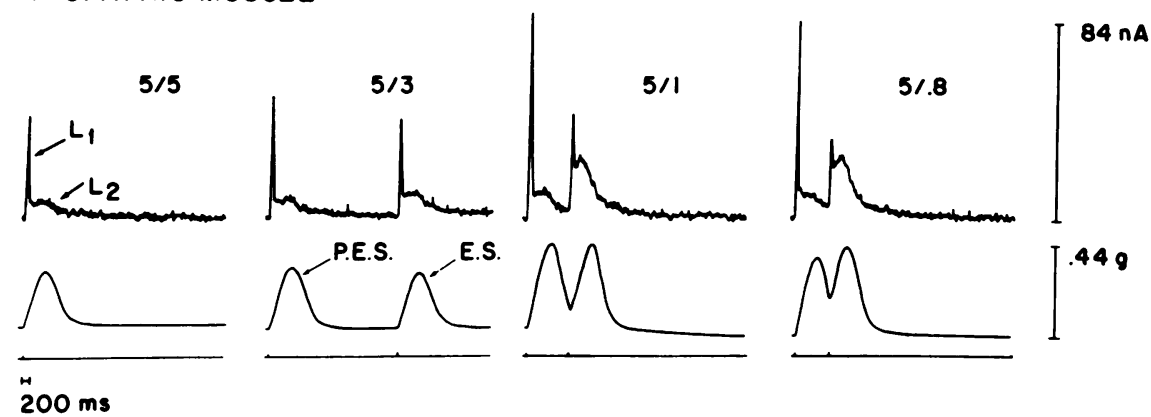

Figure 1. Experimental protocol for postextrasys tolic potentiation (P.E.S.P.) E.s.i., extrasystolic interval; P.e.s.i., interval between the premature stimulus and the following postextrasystole; $P$.E.S., potentiated contraction; and E.S., extrasystole. The conditioned contraction $(C)$ always occurred at a $0.2-\mathrm{Hz}$ stimulation rate. The middle panels illustrate postextrasystolic potentiation in a control muscle. Noisy traces reflect calcium signals and are reported in nanoamperes of anoda current. Smoother traces reflect associated isometric contractions. The lower panels are from a myopathic muscle. Components of the calcium transient are labeled $L_{1}$ and $L_{2}$. 
Cumulative concentration-response relationships were determined for increasing concentrations of extracellular calcium $\left(\left[\mathrm{Ca}^{2+}\right]_{0}\right)$ 1-16 $\mathrm{mM}$, at $0.33-\mathrm{Hz}$ stimulation. Phosphate was removed from the bathing medium during these determinations to avoid calcium precipitation. To determine frequency-response relationships, muscles were stimulated between 0.01 and $1 \mathrm{~Hz}$. The order of the experimental protocol was varied to avoid interaction effects; there was no difference as a result of the sequencing of experimental protocols.

Tetanization. The use of brief periods of rapid pacing followed by a pause has been reported to evoke maximal force of contraction (18). 10 additional right ventricular muscles were studied from myopathic hearts (six hearts were from patients with idiopathic dilated cardiomyopathy, three hearts from patients with chronic volume overload, and one heart from a patient with ischemic heart disease). Tetanus was induced by stimulating muscles at $15-20 \mathrm{~Hz}$ for $4-6 \mathrm{~s}$ with stimulus pulses of 50-ms duration. Tetani were elicited after a basal stimulation at $0.33 \mathrm{~Hz}$. Periods of tetanus were separated by 5 -min intervals during which muscles were stimulated at $0.33 \mathrm{~Hz}$. Tetani were then elicited with $0-, 5-$, or 20-s delays after basal stimulation at $1 \mathrm{~Hz}$. Steady-state force-calcium relationships at varying $\left[\mathrm{Ca}^{2+}\right]_{0}(1-16 \mathrm{mM})$ were determined from the tetanized preparations.

Chemicals. The following drugs and chemicals were used: calcium chloride (British Drug Houses Chemicals Ltd., Poole, England), forskolin (Calbiochem-Behring Corp., La Jolla, CA), and isoproterenol (Sigma Chemical Co., St. Louis, MO). The aequorin used in these experiments was purchased from the laboratory of Dr. J. R. Blinks at the Mayo Foundation in Rochester, MN. The concentration of each drug or chemical is expressed as final bath concentration.

Statistics. The $t$ test for paired and unpaired data was used for statistical analysis. Two way analysis of variance using repeated measures followed by Newman-Keuls pairwise comparison was used when appropriate. Mean and SEM are reported. A $P$ value $<0.05$ was considered significant.

\section{Results}

Calcium transients in control and myopathic human myocardium. In control human myocardium the calcium transient is monophasic ( $L_{1}$ in Fig. 1). In contrast, the calcium transient from myopathic tissue consists of two components $\left(L_{1}\right.$ and $L_{2}$ in Fig. 1). The delayed component, $L_{2}$, appears to be caused by abnormal sarcoplasmic reticulum calcium handling and enhanced calcium flux across the sarcolemma $(7,8)$.

Intracellular calcium levels in control and myopathic myocardium. Table I lists resting, end-diastolic, and peak intracellular calcium levels for control and myopathic tissues. Intracellular calcium concentration for the second component $\left(L_{2}\right)$ in myopathic tissue is also included in Table I. Myopathic tissue demonstrated significantly higher resting and end-diastolic calcium levels. Peak calcium levels were not significantly different between control and myopathic tissue at any $\left[\mathrm{Ca}^{2+}\right]_{0}$.

Postextrasystolic potentiation: summation of contractions. Fig. 1 illustrates the experimental protocol and representative data from experiments in control and myopathic trabeculae. Postextrasystolic potentiation produced no increase in resting tension or calcium and summation was never seen in control muscles. As the extrasystolic interval was reduced in control and myopathic muscle, potentiation of the conditioned beat (postextrasystole) and associated calcium transient developed and a new steady state was attained (Fig. 1). Changes in force and intracellular calcium occurred on a beat-to-beat basis. The extrasystole was associated with an increase in amplitude of the contractile response and no significant change in the amplitude of the associated calcium transient at intervals $\geq 700$ ms. At intervals $\leq 700 \mathrm{~ms}$ the amplitude of the contraction and associated peak $\left[\mathrm{Ca}^{2+}\right]_{i}$ decreased. When extrasystoles occurred at extrasystolic intervals $\leq 700 \mathrm{~ms}$, the postextrasystole developed the same force as the conditioned contraction. Peak amplitude of the calcium transient also returned to a level similar to that which occurred at the conditioning frequency.

In myopathic tissue there was often summation of the contractile response with the extrasystole being potentiated more than the postextrasystolic response $(n=6)$ (Fig. 1). The fact that summation never occurred in control myocardium during postextrasystolic potentiation under similar conditions supports the observation that sarcoplasmic reticulum calcium handling and, possibly, sarcolemmal calcium flux are abnormal in myopathic human myocardium (7). Summation of the isometric contractions was associated with fusion of the calcium transients. The calcium transient associated with the extrasystole did not start from resting levels, but fused with the declining phase of the postextrasystole calcium transient. This, in conjunction with the potentiation of $L_{2}$, suggests that summation of the extrasystole is due to abnormally increased $\left[\mathrm{Ca}^{2+}\right]_{\mathrm{i}}$.

Conduction and latency. The relationship of muscle refractoriness to stimulation frequency was demonstrated by reducing the extrasystolic interval below the optimal range for potentiation. The effective refractory period was defined as the minimal extrasystolic interval that did not result in an extrasystole. There was no significant difference between the refractory period for myopathic $(n=9)$ and control tissue $(n=6)$ $(630 \pm 60$ and $730 \pm 60 \mathrm{~ms}$, respectively, $P>0.1)$.

Table I. Intracellular Calcium Concentrations

\begin{tabular}{lccccc}
\hline & Frequency & Peak $\left[\mathrm{Ca}^{2+}\right]_{i}$ & $\begin{array}{c}\text { End-diastolic } \\
{\left[\mathrm{Ca}^{2+}\right]_{i}}\end{array}$ & $\begin{array}{c}L_{2} \text { Peak } \\
{\left[\mathrm{Ca}^{2+}\right]_{i}}\end{array}$ & $\begin{array}{c}\text { Resting } \\
{\left[\mathrm{Ca}^{2+}\right]_{i}}\end{array}$ \\
\hline Control & $H z$ & & & $\mu M$ & $0.23 \pm 0.05$ \\
Myopathic & 0.33 & $1.20 \pm 0.40$ & $0.25 \pm 0.02$ & - & $0.35 \pm 0.08^{*}$ \\
Control & 0.33 & $1.26 \pm 0.29$ & $0.37 \pm 0.01^{*}$ & $1.21 \pm 0.20$ & - \\
Myopathic & 1.0 & $2.36 \pm 0.40$ & $0.26 \pm 0.01$ & $1.18 \pm 0.28$ \\
\end{tabular}

Measurements were taken while the muscle was contracting under steady-state conditions at the frequencies indicated. Resting measurements were done in unstimulated muscle. All measurements are listed as mean $\pm \mathrm{SE}$. $\left[\mathrm{Ca}^{2+}\right]_{0}=2.5 \mathrm{mM}$. Note that a second component $\left(L_{2}\right)$ was present only in myopathic muscles. Control $(n=6)$; myopathic $(n=8$ : five idiopathic cardiomyopathy and three ischemic). *Significance at $P$ $\leq 0.05$ compared with values in control muscles. 
Time to initiation of contraction (measured as time from stimulus artifact to start of contraction) was longer for myopathic muscles at all frequencies of stimulation studied. At $0.33-$ and $1-\mathrm{Hz}$ stimulation frequencies, time to initiation was $48.3 \pm 5.8$ and $48.7 \pm 7 \mathrm{~ms}$, respectively, for myopathic tissue and $24.2 \pm 1.6$ and $20.8 \pm 2.1 \mathrm{~ms}$ for control tissue. The time to initiation of contraction for the postextrasystole and extrasystole in myopathic tissue was also longer: $38.1 \pm 2.0$ and $45.6 \pm 4.0 \mathrm{~ms}$, respectively, vs. $27.3 \pm 1.30$ and $26.0 \pm 3.4 \mathrm{~ms}$, respectively, for control muscles. For myopathic and control muscle the initiation time for the conditioned contraction $(0.2$ $\mathrm{Hz}$ ) was $52.3 \pm 5.4$ and $25.8 \pm 4.6 \mathrm{~ms}$, respectively.

There was no significant difference in the initiation times between conditioned responses and postextrasystole in control muscles. However, in myopathic tissue, time to initiation of the postextrasystole was significantly briefer than for conditioned contractions $(P<0.01)$. The reduced initiation time for the potentiated contraction in myopathic tissue suggests a closer correlation between the initiation of depolarization and contraction. This could reflect earlier and/or greater availability of calcium at the level of the myofilaments as is suggested by the associated potentiation of $\mathrm{L}_{2}$ (see Fig. 3) or could arise as a result of decreased muscle compliance.

Relationship of restitution and postextrasystolic potentiation curves. The time course of development of extrasystolic contractile strength was represented by restitution curves. The increase in strength of contraction of the postextrasystole with shortening of the extrasystolic interval was represented by postextrasystolic potentiation curves. Curves were generated as described by Wier and Yue (10) by plotting peak developed force $\left(F_{\max }\right)$ as a function of the extrasystolic interval (Fig. 2). $F_{\max }$ was normalized to steady-state values. As the extrasystolic interval was shortened, there was an increase in $F_{\max }$ for both the extrasystole and postextrasystole in control and myopathic tissue.

Monoexponential functions were fitted to pooled data by a nonlinear least-squared error algorithm. The strength of contraction approximated a monoexponential function $(P$ $\leq 0.05$ ), as previously described by Wier and Yue (10) in ferret myocardium. At shorter extrasystolic intervals, however, $F_{\max }$ values tended to diverge from the curve. The time constants for restitution and postextrasystolic potentiation were similar for control and myopathic tissue (Fig. 2).

Relationship of $[\mathrm{Ca}]_{i}$ to restitution and postextrasystolic potentiation curves. The relationship of intracellular calcium to restitution and postextrasystolic potentiation curves is illustrated in Fig. 3. Calcium transients were normalized to peak intracellular calcium values for steady-state conditioned beats $(C)$. The relationship of peak $\left(L_{1}\right)$ calcium transients to postextrasystolic potentiation curves in control and myopathic tissue paralleled that of the contractile response (Fig. 2) but did not parallel the $F_{\max }$ restitution curves (Fig. 3). However, in myopathic tissue both the restitution and postextrasystolic potentiation curves for the delayed calcium transient, $L_{2}$, paralleled the corresponding tension responses.

Fig. 4 shows plots of $F_{\max }$ versus peak intracellular calcium
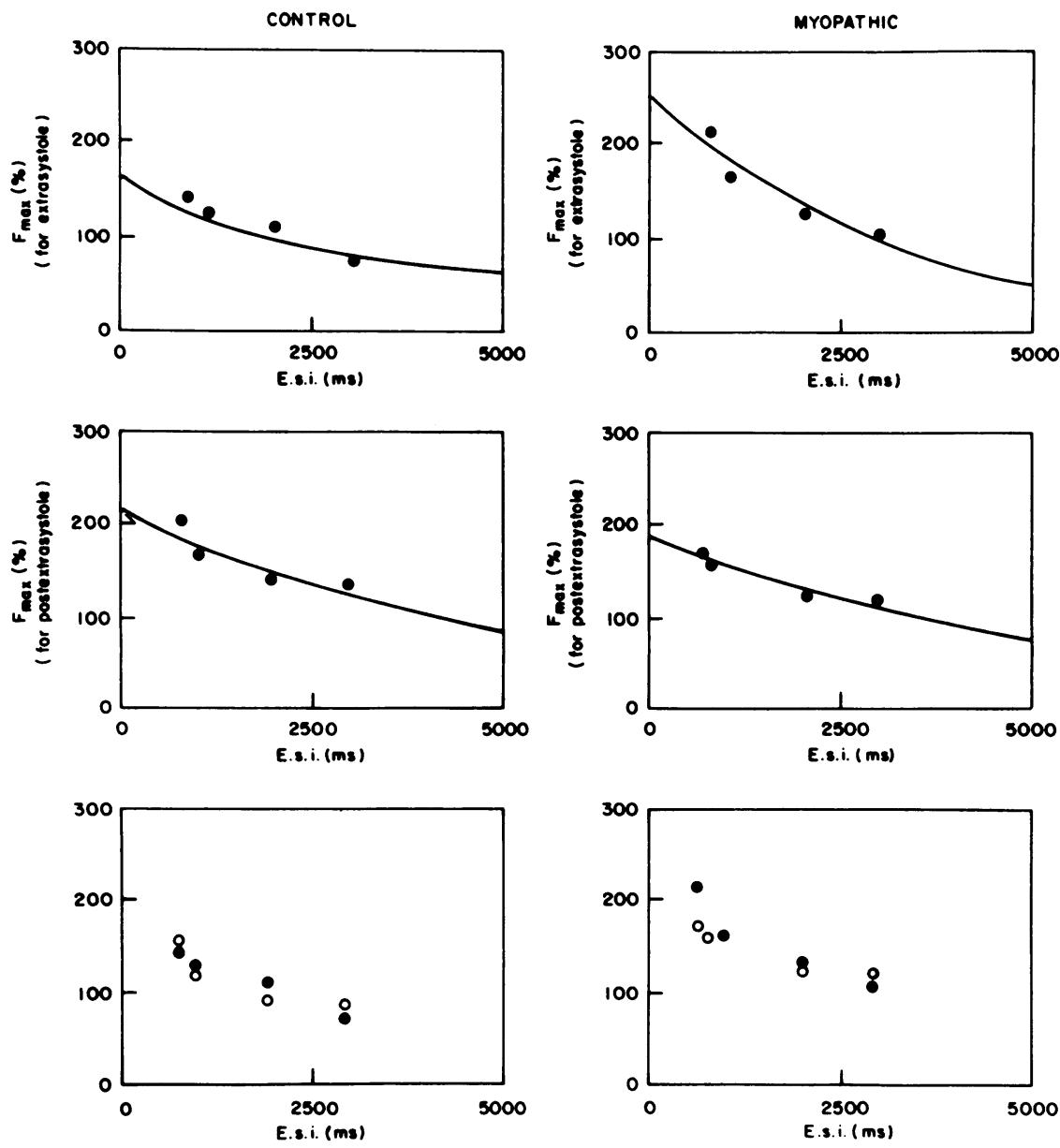

Figure 2. Plots of peak developed force $\left(F_{\max }\right)$ as a function of extrasystolic interval (E.s.i.). Top left, middle, and bottom are from control muscles. Top right, middle, and bottom are from myopathic muscles. Top panels are restitution curves and middle panels postextrasystolic potentiation curves. Lowermost panels are after axis offsetting showing superimposition of points for the postextrasystole and the extrasystole. The figure is derived from control $(n=6)$ and myopathic ( $n=9$ : seven idiopathic cardiomyopathy, two ischemic cardiomyopathy) sets of curves (restitution and postextrasystolic potentiation expressed as mean of all pooled data). The $R$ values were $P<0.05$ indicating that the curves were well fitted by the exponential form. Time constants and $y$ intercepts for the restitution curves for control and myopathic tissue were 4,540 and 4,300 $\mathrm{ms} ; \mathrm{Y}^{\circ}=145$ and 207 , respectively. Time constants and $y$-intercepts for postextrasystolic potentiation curves were 5,400 and $5,170 \mathrm{~ms}$; $\mathrm{Y}^{\circ}=216$ and 196 , respectively. 

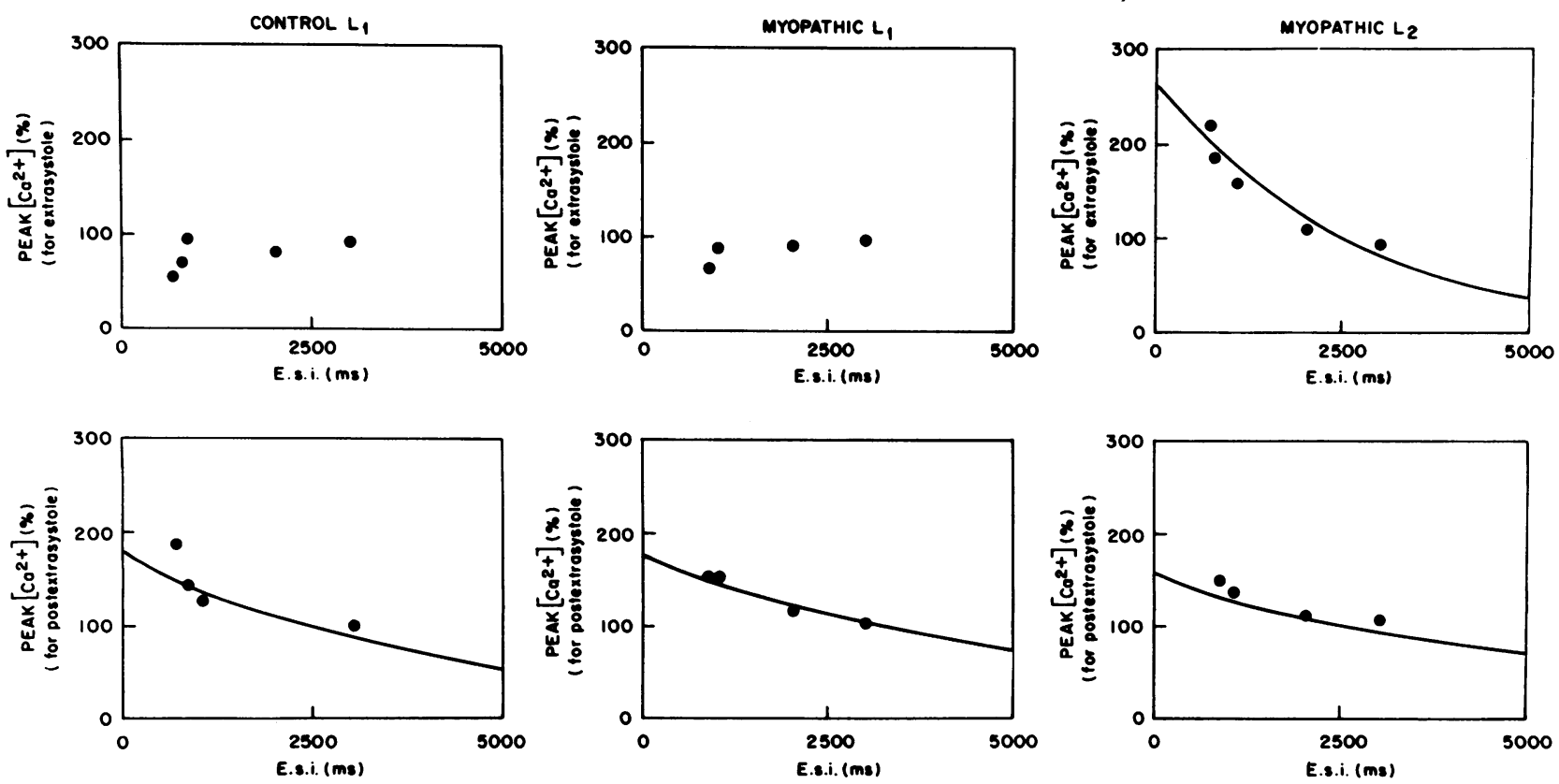

Figure 3. Restitution (upper panels) and postextrasystolic potentiation curves (lower panels) for peak intracellular calcium as a function of extrasystolic interval (E.s.i.). Left panels represent $L_{1}$ for control tissue. Middle panels represent $L_{1}$ for myopathic tissue and right panels represent $\mathrm{L}_{2}$ for myopathic tissue. The figure is derived from control $(n=6)$ and myopathic $(n=9$ : seven idiopathic cardiomyopathy; two ischemic cardiomyopathy) sets of curves. Data were analyzed as in Fig. 2. Time constants and $y$-intercepts for regression of calcium in postextrasystolic potentiation curves for $L_{1}$ in control and myopathic tissue were 4,900 and 4,300 ms; $Y^{\circ}=186$ and 204, respectively, and for $L_{2}$ in myopathic tissue $\tau$ was $4,200 \mathrm{~ms}$ with $Y^{\circ}=122$. Restitution curves for $L_{2}$ in myopathic tissue had $\tau=2,710 \mathrm{~ms}$ and $Y^{\circ}=259$.

concentrations for extrasystolic and postextrasystolic contractions. For the postextrasystole $L_{1}$ shifted to higher intracellular calcium $(\mathrm{pCa})$ as the extrasystolic interval was shortened. $L_{2}$ for the postextrasystole demonstrated a similar shift. $L_{1}$ associated with the extrasystole did not change. However, intracel- lular calcium associated with $L_{2}$ of the extrasystole shifted to a higher $\mathrm{pCa}$ as extrasystolic interval was shortened.

Effect of postextrasystolic potentiation and restitution on time course of contraction. There was no significant difference in the time course of potentiated contractions (postextrasys-
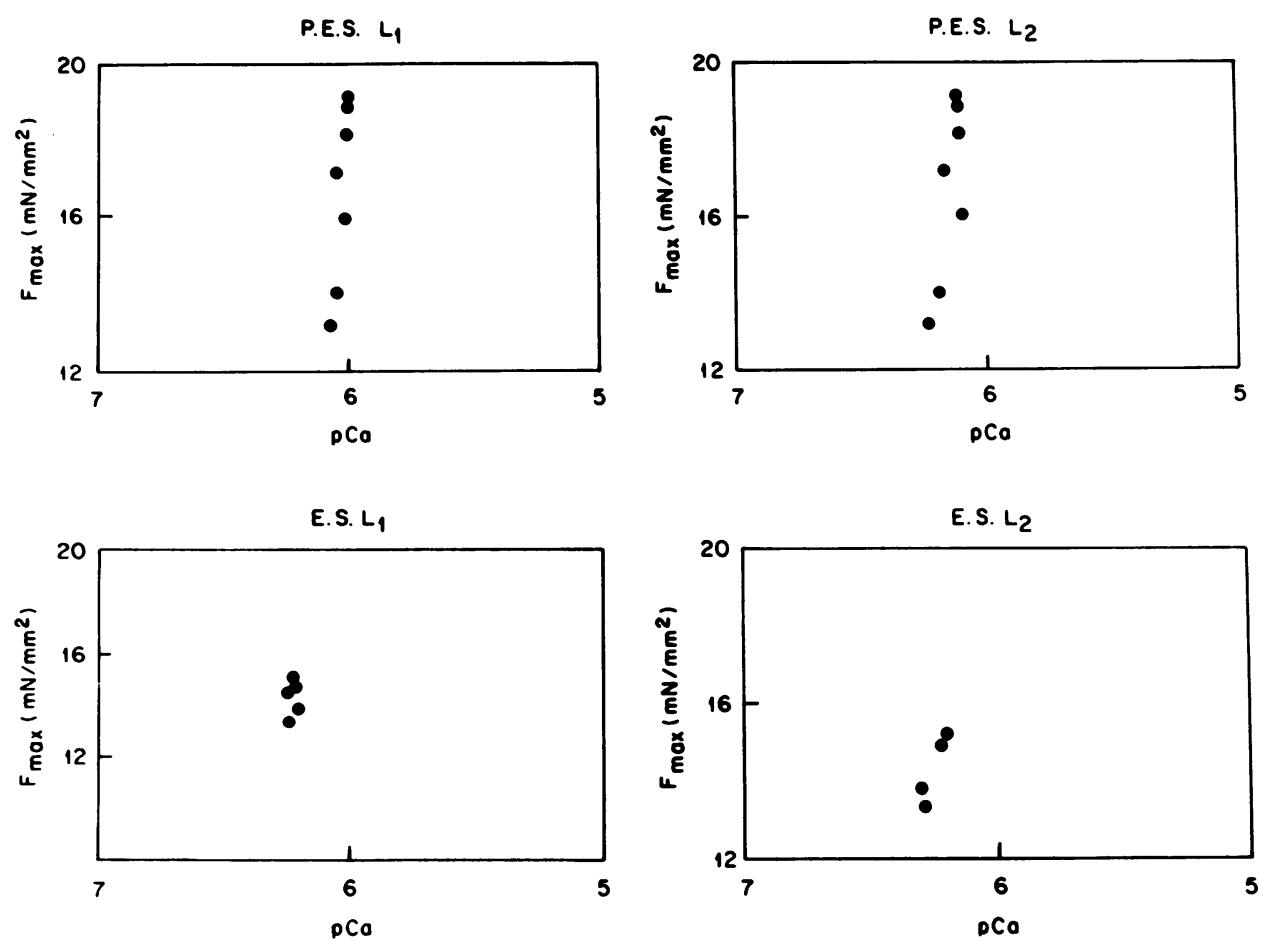

Figure 4. Upper panels demonstrate the effect of postextrasystolic (P.E.S.) potentiation on force and $\left[\mathrm{Ca}^{2+}\right]_{\mathrm{i}}$ in a myopathic muscle. Lower panels illustrate the effects on force and $\left[\mathrm{Ca}^{2+}\right]_{i}$ of extrasystole (E.S.). Note $L_{2}$ for P.E.S. is at lower $\left[\mathrm{Ca}^{2+}\right]_{i}$. There is no change in peak $\left[\mathrm{Ca}^{2+}\right]_{i}$ of $L_{1}$ associated with the E.S., but $L_{2}$ shifts to higher $\left[\mathrm{Ca}^{2+}\right]_{i}$. 
toles) or of the associated intracellular calcium transients with increasing prematurity of the extrasystoles for control versus myopathic tissue (Table II). The extrasystole demonstrated no significant change in the time to peak tension until relatively short extrasystolic interval, but did show abbreviation of relaxation time with decreasing extrasystolic interval (Table II). However, the maximum rate of tension development, as reflected by an increase in peak developed tension, increased with prematurity until an "optimal" interstimulus interval was reached and then declined. All data in Table II were derived from contractions preceded by activations that were not fused to the postextrasystole. These beats were, however, not fully potentiated. In some cases we extrapolated to baseline the rate of relaxation of fully potentiated beats that were fused with the premature extrasystole and could not demonstrate a change in the time course of contraction. In contrast to the response at the optimal extrastimulus interval, increasing the frequency of stimulation to $1 \mathrm{~Hz}$ resulted in a marked abbreviation in the time to peak tension and relaxation phase.

Table II. A. Percent Change in Time Course of Contraction of Postextrasystolic Potentiation

\begin{tabular}{lccc}
\hline & TPT & $\mathrm{RT}_{\mathbf{5 0}}$ & $\mathrm{RT}_{\mathbf{8 0}}$ \\
\hline & & $\%$ & \\
Control & $104 \pm 2$ & $89 \pm 3$ & $94 \pm 3$ \\
Myopathic & $98 \pm 2$ & $98 \pm 3$ & $99 \pm 3$ \\
& TPL & $\mathrm{RL}_{\mathbf{5 0}}$ & $\mathrm{RL}_{\mathbf{8 0}}$ \\
\hline Control & $96 \pm 2$ & $91 \pm 8$ & $85 \pm 7$ \\
Myopathic & $99 \pm 3$ & $91 \pm 4$ & $87 \pm 3$ \\
\hline
\end{tabular}

B. Percent Change in Time Course of Premature Contraction (Extrasystole)

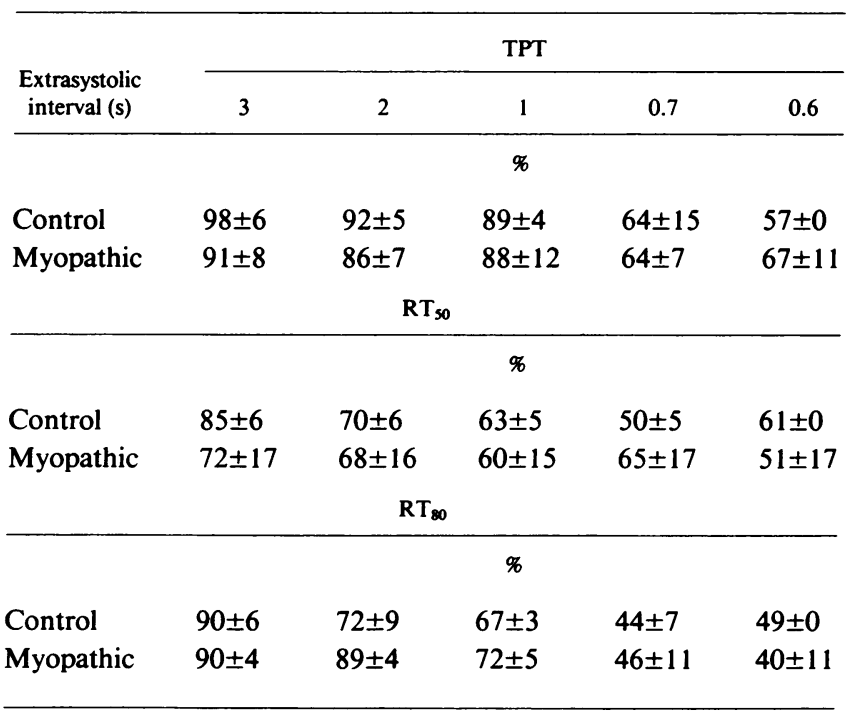

Abbreviations: TPT, time to peak tension; $\mathrm{RT}_{50}$ and $\mathrm{RT}_{80}$, time to $50 \%$ and $80 \%$ relaxation; TPL, time to peak light; $R L_{50}$ and $R L_{80}$, time to $50 \%$ and $80 \%$ decline from peak light. All values were normalized to $0.2-\mathrm{Hz}$ stimulation frequency. All values are listed as mean \pm SE. Control $(n=6)$ and myopathic $(n=9$ : seven idiopathic cardiomyopathy, two ischemic cardiomyopathy).
Effect of postextrasystolic potentiation on resting tension and intracellular calcium. Premature stimuli did not affect resting tension of potentiated contractions. Resting calcium associated with the potentiated contraction was not affected in myopathic or control tissue, but in myopathic tissue the resting calcium level associated with the extrasystole was often elevated, resulting in summation (Fig. 1). Increasing the frequency of stimulation to $1 \mathrm{~Hz}$ resulted in an increase in resting tension and an increase in resting calcium levels in some myopathic muscles (see below).

Frequency potentiation: The effect on tension development and intracellular calcium. To investigate the relationship between peak isometric twitch force and peak calcium we generated calcium concentration response curves and frequency response curves in the same muscles. Peak tension increased with increasing $\left[\mathrm{Ca}^{2+}\right]_{0}$ as previously reported (7) and was associated with an increase in $\left[\mathrm{Ca}^{2+}\right]_{i}$. Increasing the $\left[\mathrm{Ca}^{2+}\right]_{0}$ at a stimulation frequency of $0.33 \mathrm{~Hz}$ resulted in an increase in resting calcium and tension in 8 of 20 myopathic muscles.

Control and myopathic muscles (Fig. 5) demonstrated an increase in peak intracellular calcium with increasing stimulation frequencies. In the presence of physiologic $\left[\mathrm{Ca}^{2+}\right]_{0}(2.5$ $\mathrm{mM}), 17$ of 20 myopathic muscles demonstrated an increase in resting tension and intracellular calcium when the frequency of stimulation was increased to $\geq 1 \mathrm{~Hz}$. This could only be demonstrated in the presence of high extracellular calcium concentration $(16 \mathrm{mM})$ in 7 of 18 control muscles, and suggests that high $\left[\mathrm{Ca}^{2+}\right]_{0}$ can result in toxicity in normal myocardium. All control muscles showed positive augmentation as the frequency of stimulation was increased. The response of myopathic muscles to increased frequency of stimulation was variable: four demonstrated diminished augmentation, seven demonstrated a negative force-frequency relationship, and nine demonstrated a positive force-frequency relationship. In the nine muscles that demonstrated positive augmentation the response was still blunted compared to control muscles.

In an effort to compare the amount of calcium released in the presence of maximal activation $\left(16 \mathrm{mM}\left[\mathrm{Ca}^{2+}\right]_{\mathrm{o}}\right)$ and at $1-\mathrm{Hz}$ stimulation frequency, we calculated peak intracellular calcium as a percent of peak intracellular calcium at $16 \mathrm{mM}$ $\left[\mathrm{Ca}^{2+}\right]_{0}$ in the same muscles stimulated at $0.33 \mathrm{~Hz}$. In control tissue the peak calcium peak tension relationship at $1-\mathrm{Hz}$ stimulation frequency was similar to that observed in muscles stimulated at $0.33 \mathrm{~Hz}$ in $16 \mathrm{mM}$ calcium. Peak tension at $1-\mathrm{Hz}$
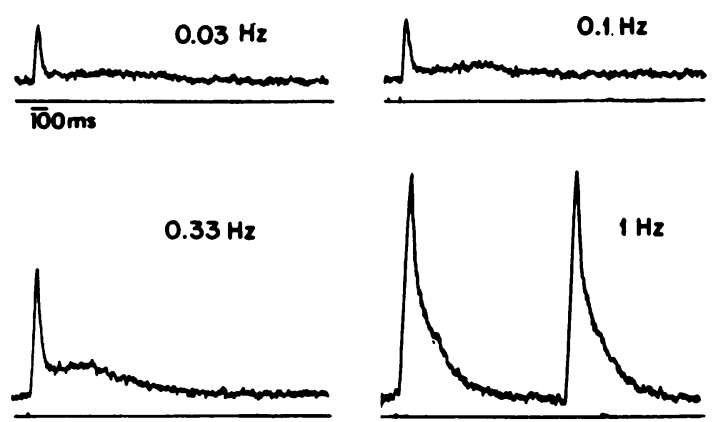

Figure 5. The effect on intracellular calcium in response to varying the frequency of stimulation for a myopathic muscle in $2.5 \mathrm{mM}$ $\left[\mathrm{Ca}^{2+}\right]_{0}$. 
stimulation was $71 \pm 9 \%$ and $\left[\mathrm{Ca}^{2+}\right]_{\mathrm{i}}$ was $82 \pm 15 \%$ of the control muscle response at $0.33 \mathrm{~Hz}$ in $16 \mathrm{mM}\left[\mathrm{Ca}^{2+}\right]_{\mathrm{o}}(n=10 ; P$ $=0.20$ ). In myopathic tissue, peak tension was $59 \pm 10 \%$ and $\left[\mathrm{Ca}^{2+}\right]_{\mathrm{i}}$ was $104 \pm 23 \%$ at $1-\mathrm{Hz}$ stimulation rates $(n=10 ; P$ $=0.03)$. Peak $\left[\mathrm{Ca}^{2+}\right]_{\mathrm{i}}$ and tension responses were not significantly different between control and myopathic tissue $(P$ $=0.20$ ).

Relationships between calcium concentration, peak tension, and stimulation frequency were evaluated using linear regression analysis. For the frequency response curve there was a linear correlation $(r=0.95)$ between peak calcium and peak tension (Fig. 6). For increasing concentrations of extracellular calcium there was a similar correlation between peak calcium (i.e., $L_{1}$ and $L_{2}$ in myopathic tissue) and peak tension (Fig. 6).

Force potentiation curves were generated (Fig. 7). Peak calcium transient and tension responses at different stimulation frequencies were normalized to their respective steadystate values at $0.33 \mathrm{~Hz}$. The curves fit a double-exponential function. At faster stimulation frequencies there was a significant increase in peak light and tension in control and myopathic muscles (Fig. 7). Table III summarizes all pooled data. In myopathic tissue the force-frequency relationship was further blunted after normalization as percent of $F_{\max }$ at $0.01 \mathrm{~Hz}$. At $1-\mathrm{Hz}$ stimulation frequency, $F_{\max }$ in control and myopathic muscles were $1025 \pm 224 \%$ and $376 \pm 213 \%$, respectively, of $F_{\max }$ at $0.01 \mathrm{~Hz}$.

The lack of augmentation with increased frequency of stimulation in myopathic muscles could be explained on the basis of core hypoxia if muscle diameter exceeded the critical diameter for oxygen diffusion from the surface to the inner fibers (19). We found no correlation between peak tension at faster stimulation rates $(\geq 1 \mathrm{~Hz})$ and fiber diameter or crosssectional area in myopathic tissue. In our experiments trabecular strips with diameters as small as $0.2 \mathrm{~mm}$ and cross-sectional areas of $0.19 \mathrm{~mm}^{2}$ demonstrated lack of force augmentation.
According to Koch-Weser (19), limiting the cross-sectional areas of experimental preparations to $\leq 0.59 \mathrm{~mm}^{2}$ should avoid problems with core hypoxia. There did, however, appear to be a bimodal relationship between myocyte fiber diameter $(n=12)$ and force. Moderately hypertrophied $(\approx 23 \mu \mathrm{m})$ fibers generated less force than slightly hypertrophied fibers $(\approx 17 \mu \mathrm{m})$. These data suggest that hypertrophied myocytes could develop a "metabolic" hypoxia secondary to depletion of high energy phosphates which would explain the negative force-frequency relationship and diminished augmentation.

Effect of frequency on the time course of contraction. Myopathic human myocardium has a prolonged contractile response compared to control human myocardium $(7,20)$. The effects of increasing stimulation rate on time course of isometric contraction and associated calcium transients are summarized in Table IV. Increasing the stimulation rate resulted in abbreviation of the contractile response and of the intracellular calcium transient. Pairwise comparisons for control and myopathic muscles at the same stimulation frequency revealed significant differences (Table IV).

Effect of agents that alter cyclic AMP levels. If the altered frequency response relationship and summation observed with postextrasystolic potentiation in myopathic tissue arises as a result of altered sarcoplasmic reticulum calcium handling then agents that enhance sarcoplasmic reticulum calcium handling would be expected to produce responses more similar to those seen in control muscles. In the presence of isoproterenol or forskolin which enhance sarcoplasmic reticulum calcium handling by increasing cyclic AMP, the biphasic calcium transient seen in myopathic tissue became monophasic (only $L_{1}$ remained). In addition, in the presence of these agents myopathic muscles stimulated at $1 \mathrm{~Hz}$ demonstrated no increase in resting calcium or resting tension. Conversely, the addition of carbachol, which decreases intracellular cyclic AMP, resulted in an increase in resting calcium and tension (data not shown).
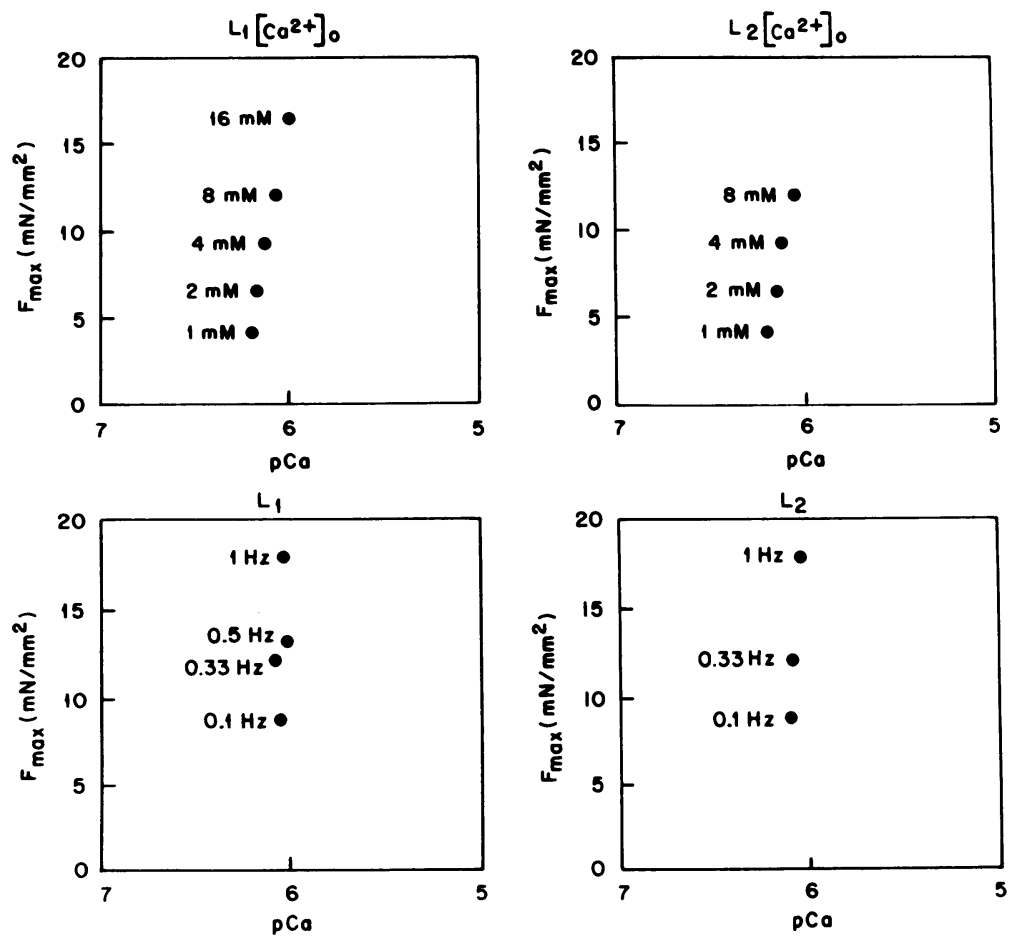

Figure 6. Top panels illustrate the relationship between increasing $\left[\mathrm{Ca}^{2+}\right]_{0}$ on peak $\left[\mathrm{Ca}^{2+}\right]_{i}(\mathrm{pCa})$ in a myopathic muscle. At high $\left[\mathrm{Ca}^{2+}\right]_{\mathrm{o}} L_{2}$ becomes fused with $L_{1}$. Top right panel illustrates the effect on $L_{2}$. Lower panels illustrate the effect of varying stimulation frequency on the peak $\left[\mathrm{Ca}^{2+}\right]_{\mathrm{i}}$ at $\left[\mathrm{Ca}^{2+}\right]_{\mathrm{o}}=2.5 \mathrm{mM}$. Lower right hand panel illustrates the effect on $L_{2}$. At $1-\mathrm{Hz}$ stimulation frequency, $L_{2}$ becomes fused with $L_{1}$. 

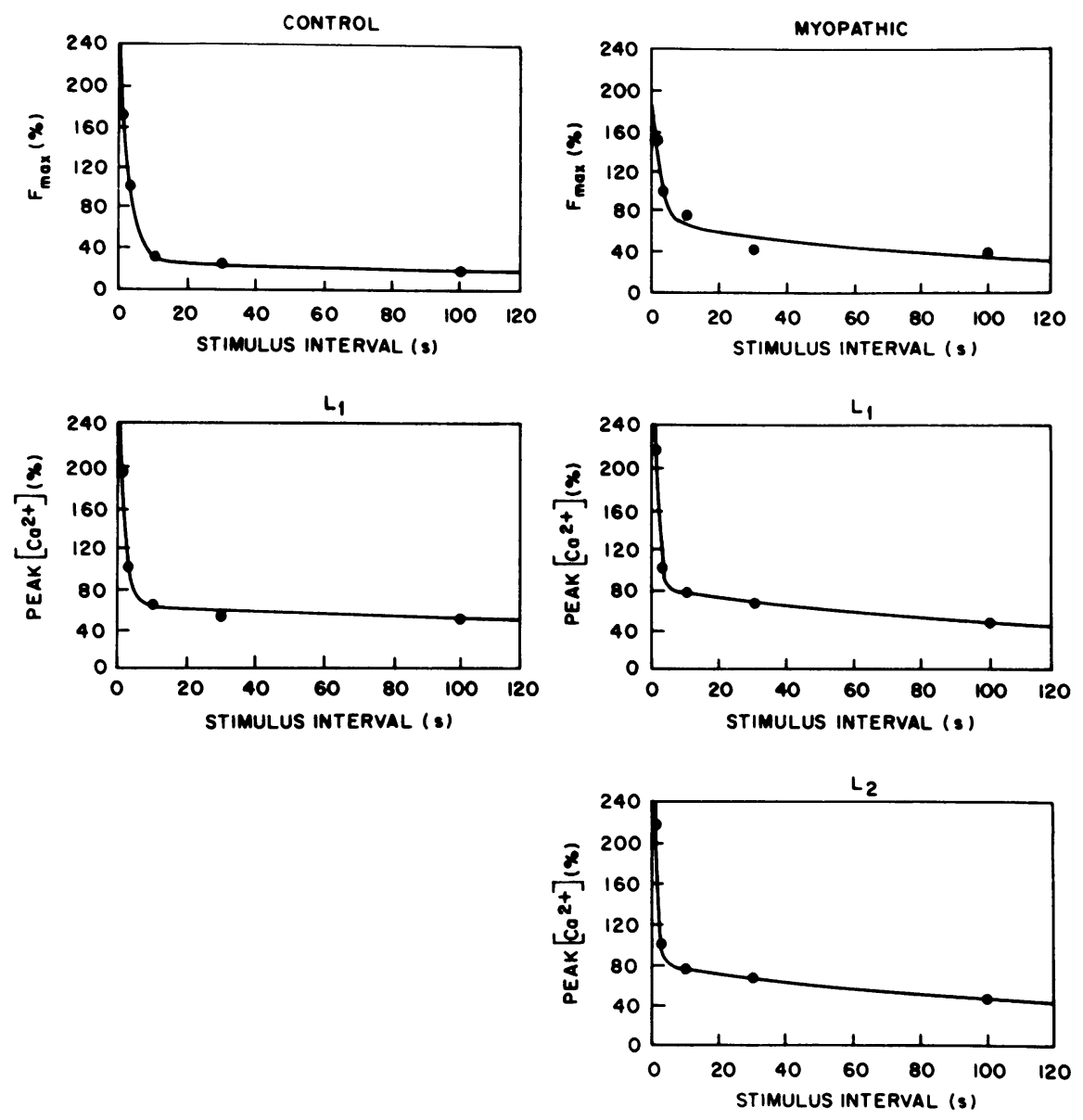

Figure 7. Percent $F_{\max }$ and $\left[\mathrm{Ca}^{2+}\right]_{i}$ for frequency potentiation with values normalized to peak isometric force and calcium at $\mathbf{0 . 3 3}$ $\mathrm{Hz}$, respectively. Left panels: control. Right panels: myopathic tissue.

Further, myopathic muscle exposed to isoproterenol no longer exhibited an augmented extrasystole at short extrasystolic intervals but demonstrated postextrasystolic potentiation at short extrasystolic intervals similar to what was observed in control muscles (Fig. 8).

Table III. Summary of Exponential Regression of Frequency Curves

\begin{tabular}{lccc}
\hline & Force $\left(\tau_{1}\right)$ & Force $\left(\tau_{2}\right)$ \\
\hline & & $s$ & \\
Control & 2.84 & & 289 \\
Myopathic & 2.25 & & 154 \\
& $\mathrm{~L}_{1}\left(\tau_{1}\right)$ & & $\mathrm{L}_{1}\left(\tau_{2}\right)$ \\
\hline & & $s$ & \\
Control & 1.68 & & 475 \\
Myopathic & 1.10 & & 185 \\
& $\mathrm{~L}_{2}\left(\tau_{1}\right)$ & & $\mathrm{L}_{2}\left(\tau_{2}\right)$ \\
\hline & & $s$ & \\
Myopathic & 0.8 & & 751 \\
\hline
\end{tabular}

Summary of double regression of frequency potentiation curves. Control $(n=15)$ and myopathic $(n=12$ : eight idiopathic cardiomyopathy, three ischemic cardiomyopathy, one hypertrophic cardiomyopathy).
The fact that summation could be reversed with agents that facilitate sarcoplasmic reticulum calcium handling suggests that sarcoplasmic reticulum function is impaired in myopathic human myocardium. While it is true that these agents also increase slow inward current, their predominant effect is on phosphorylation of the sarcoplasmic reticulum with resultant enhanced uptake of calcium $(21,22)$. This enhancement of sarcoplasmic reticulum function would then explain why the biphasic calcium transient in myopathic tissue becomes monophasic in the presence of these agents. Previous work has suggested that myopathic human myocardium is deficient in cyclic AMP (20).

Steady-state force-calcium relationships: tetanization. We have previously shown that there is no difference between control and myopathic myocardium in steady-state force calcium relationships after basal stimulation at $0.33 \mathrm{~Hz}(23)$. In the present experiments steady-state force-calcium relationships were derived after stimulating the muscle at frequencies of 0.33 and $1 \mathrm{~Hz}$. Mean muscle diameter for these experiments was $0.7 \pm 0.1 \mathrm{~mm}$; mean length $7.7 \pm 0.7 \mathrm{~mm}$; mean myocyte diameter $20.2 \pm 0.6 \mu \mathrm{m}$. Stimulation of myopathic muscles with smaller myocyte fiber diameters at $0.33 \mathrm{~Hz}$ followed by delays in activation by tetanization suppressed postrest potentiation. This was associated with decreases in the $\left[\mathrm{Ca}^{2+}\right]_{\mathrm{i}}$ transient and in force development. Tetani after periods of stimulation at $1 \mathrm{~Hz}$ were associated with larger $\left[\mathrm{Ca}^{2+}\right]_{i}$ transients but similar or diminished force compared with tetani after 0.33 $\mathrm{Hz}$ stimulation. This finding suggests that at higher frequencies there is a decrease in myofilament calcium sensitivity in 
Table IV. Frequency-related Changes

in Time Course Measurements

\begin{tabular}{|c|c|c|c|c|}
\hline \multirow{2}{*}{$\begin{array}{l}\text { Frequency } \\
(\mathbf{H z})\end{array}$} & \multicolumn{4}{|c|}{ TPT } \\
\hline & 1 & 0.5 & 0.33 & 0.1 \\
\hline \multirow{3}{*}{$\begin{array}{l}\text { Control } \\
\text { Myopathic }\end{array}$} & \multicolumn{4}{|c|}{$m s$} \\
\hline & $221 \pm 6$ & $240 \pm 10$ & $280 \pm 9$ & $254 \pm 24$ \\
\hline & $300 \pm 16^{*}$ & $330 \pm 46^{*}$ & $390 \pm 18^{*}$ & $409 \pm 58^{*}$ \\
\hline \multirow{2}{*}{$\begin{array}{l}\text { Frequency } \\
(\mathrm{Hz})\end{array}$} & \multicolumn{4}{|c|}{$\mathrm{RT}_{\text {so }}$} \\
\hline & 1 & 0.5 & 0.33 & 0.1 \\
\hline \multirow{3}{*}{$\begin{array}{l}\text { Control } \\
\text { Myopathic }\end{array}$} & \multicolumn{4}{|c|}{$m s$} \\
\hline & $155 \pm 6$ & $190 \pm 13$ & $243 \pm 19$ & $292 \pm 39$ \\
\hline & $205 \pm 11^{*}$ & $223 \pm 19$ & $283 \pm 17$ & $372 \pm 29$ \\
\hline \multirow{2}{*}{$\begin{array}{l}\text { Frequency } \\
(\mathrm{Hz})\end{array}$} & \multicolumn{4}{|c|}{$\mathrm{RT}_{80}$} \\
\hline & 1 & 0.5 & 0.33 & 0.1 \\
\hline \multirow{4}{*}{$\begin{array}{l}\text { Control } \\
\text { Myopathic }\end{array}$} & \multicolumn{4}{|c|}{$m s$} \\
\hline & $248 \pm 14$ & $312 \pm 26$ & $395 \pm 37$ & $515 \pm 62$ \\
\hline & $320 \pm 18^{*}$ & $343 \pm 28$ & $451 \pm 27$ & $582 \pm 25$ \\
\hline & \multicolumn{4}{|c|}{ TPL } \\
\hline \multirow{2}{*}{$\begin{array}{l}\text { Frequency } \\
\quad(\mathrm{Hz})\end{array}$} & 1 & 0.5 & 0.33 & 0.1 \\
\hline & \multicolumn{4}{|c|}{$m s$} \\
\hline Control & $38 \pm 2$ & $35 \pm 2$ & $39 \pm 3$ & $24 \pm 1$ \\
\hline Myopathic & $41 \pm 4$ & $36 \pm 4$ & $47 \pm 13$ & $32 \pm 3$ \\
\hline \multirow{3}{*}{$\begin{array}{l}\text { Frequency } \\
\quad(\mathrm{Hz})\end{array}$} & \multicolumn{4}{|c|}{$\mathrm{RL}_{50}$} \\
\hline & 1 & 0.5 & 0.33 & 0.1 \\
\hline & \multicolumn{4}{|c|}{$m s$} \\
\hline Control & $93 \pm 8$ & $112 \pm 15$ & $112 \pm 15$ & $107 \pm 13$ \\
\hline Myopathic & $145 \pm 16^{*}$ & $226 \pm 63^{*}$ & $218 \pm 35^{*}$ & $143 \pm 50$ \\
\hline \multirow{3}{*}{$\begin{array}{l}\text { Frequency } \\
(\mathrm{Hz})\end{array}$} & \multicolumn{4}{|c|}{$\mathrm{RL}_{80}$} \\
\hline & 1 & 0.5 & 0.33 & 0.1 \\
\hline & \multicolumn{4}{|c|}{$m s$} \\
\hline Control & $167 \pm 14$ & $203 \pm 27$ & $208 \pm 20$ & $206 \pm 26$ \\
\hline Myopathic & $266 \pm 22^{*}$ & $358 \pm 50^{*}$ & $403 \pm 47^{*}$ & $346 \pm 73$ \\
\hline
\end{tabular}

All measurements are listed as mean \pm SE. *Significance at $P \leq 0.05$ compared to control muscles $(n=15)$. Myopathic muscles $(n=12$ : eight idiopathic cardiomyopathy, three ischemic cardiomyopathy, one hypertrophic cardiomyopathy).

myopathic muscles (Fig. 9). At 5- and 20-s delays there was an increase in peak tension with no change in intracellular calcium levels.

Effects on action potential parameters. Excitation-contraction coupling can be affected by alterations in action potential configuration. The effect of varying the frequency of stimulation on action potential parameters is summarized in Table $\mathrm{V}$. In control tissue an increase in stimulation frequency was accompanied by abbreviation of the action potential. Action potential duration (APD) ${ }^{1}$ reached steady state within a few beats

1. Abbreviations used in this paper: APD, action potential duration.

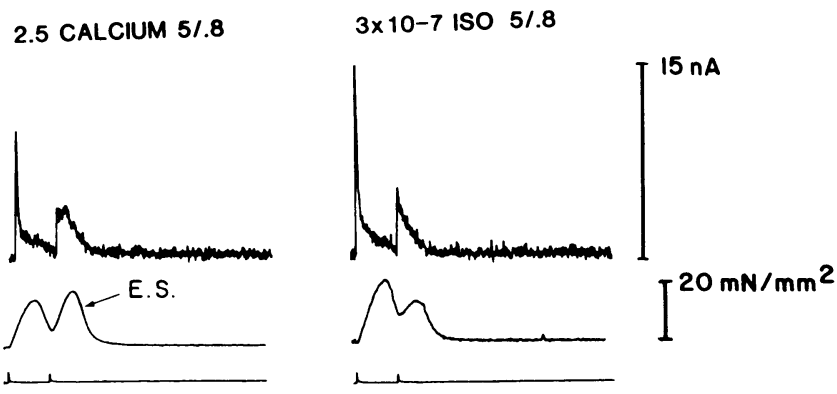

Figure 8 . Reversal of summation in a myopathic muscle by addition of isoproterenol. Extrasystole is designated $E . S$.

after a change in stimulation frequency. In contrast, at shorter cycle lengths $(1 \mathrm{~Hz})$ APD in myopathic tissue decreased more gradually to a new steady state. Abbreviation of APD was associated with diminished augmentation of tension and an increase in resting tension. Abbreviation of APD, increase in resting tension, and decreased augmentation of tension at $1-\mathrm{Hz}$ stimulation frequency were exacerbated by interventions that increased intracellular calcium such as high $\left[\mathrm{Ca}^{2+}\right]_{0}(8$ $\mathrm{mM}$ ) or addition of the inotropic agent DPI 201-106, a sodium channel agonist. Increased $\left[\mathrm{Ca}^{2+}\right]_{0}$ resulted in marked abbreviation of the action potential in myopathic tissue but not in control tissue (Fig. 10).

Fluctuations of sarcoplasmic reticulum calcium release. Spontaneous oscillations in $\left[\mathrm{Ca}^{2+}\right]_{i}$ have been reported in calcium overloaded mammalian myocardium (17). However, Fig. 11 shows significant fluctuation in peak amplitude of the calcium signals in myopathic tissue at faster stimulation frequencies. Analysis of these data revealed a periodicity in peak amplitude of the calcium transient at $0.33 \mathrm{~Hz}$ stimulation frequency in both control and myopathic tissue (Fig. 12). The periodicity of control tissue calcium transients was abolished by both faster rates of stimulation and by exposure to increased $\left[\mathrm{Ca}^{2+}\right]_{\mathrm{o}}(16 \mathrm{mM})$. In myopathic tissue, the periodicity persisted at faster stimulation where, despite a large increase in amplitude of the calcium transient, there was diminished augmentation of peak twitch force. Analysis by Fourier transform shows a reduction in periodicity with increasing stimulation frequency in control tissue. In contrast to this, the power of similar frequency components is increased in myopathic tissue.

\section{Discussion}

Calcium availability in control and myopathic human myocardium. Yue (24) reported that $\mathrm{d} F / \mathrm{d} t$ in cardiac muscle is an instantaneous function of intracellular calcium. Further, Yue et al. (25) demonstrated a linear relationship between $\left[\mathrm{Ca}^{2+}\right]_{i}$ and positive $\mathrm{d} F / \mathrm{d} t$ which was independent of both the stimulus interval and the time course of isometric tension development. Yue also found that when $\left[\mathrm{Ca}^{2+}\right]_{\mathrm{i}}$ was $0.4 \mu \mathrm{M}$ (which was $0.15-0.3 \mu \mathrm{M}$ larger than resting $\left.\left[\mathrm{Ca}^{2+}\right]\right)$ maximum negative $\mathrm{d} F / \mathrm{d} t$ was no longer a simple, instantaneous function of $\left[\mathrm{Ca}^{2+}\right]_{i}$. This value of $\left[\mathrm{Ca}^{2+}\right]_{i}$, which he termed the " $\left[\mathrm{Ca}^{2+}\right]$ offset," was the same for both physiological and slowed contractions of widely varying strengths (24). Yue (24) postulated that the linear relationship of $\mathrm{d} F / \mathrm{d} t$ to $\left[\mathrm{Ca}^{2+}\right]_{\mathrm{i}}$ during early phases of tension rise in slowed contractions was due to more 


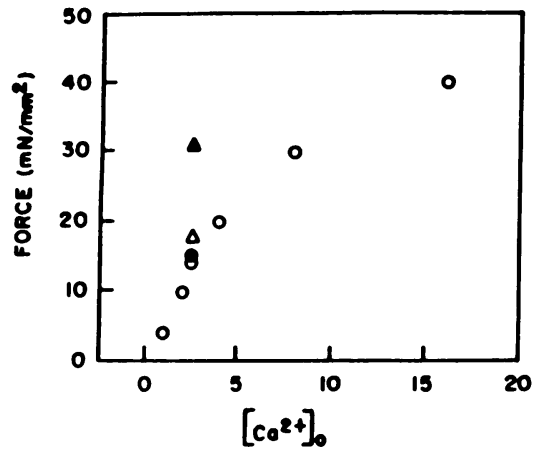

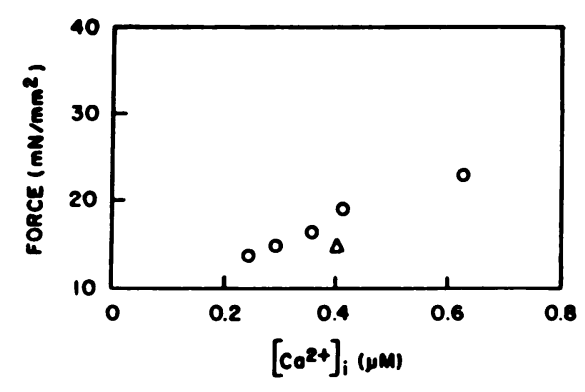

Figure 9. Left panel: steady-state force calcium relationships in myopathic tissue derived in the presence of varying $\left[\mathrm{Ca}^{2+}\right]_{0}$ $(0.5-16 \mathrm{mM})$ at a basal stimulation frequency of $0.33 \mathrm{~Hz}(0)$. Tetanizations: basal frequency $1 \mathrm{~Hz}$ : (๑) without delay; $(\Delta) 5$-s delay; ( $\triangle$ ) 20-s delay. Right panel: steadystate force-intracellular calcium relationship at varying $\left[\mathrm{Ca}^{2+}\right]_{\mathrm{i}}(\mathrm{O})$ at frequency $0.33 \mathrm{~Hz}$ compared with basal frequency of $1 \mathrm{~Hz}$ in $2.5 \mathrm{mM}\left[\mathrm{Ca}^{2+}\right]_{0}$ without delay $(\Delta)$. $\left[\mathrm{Ca}^{2+}\right]_{\mathrm{i}}$ at $1-\mathrm{Hz}$ basal stimulation rate is similar to $\left[\mathrm{Ca}^{2+}\right]_{\mathrm{i}}$ at $0.33 \mathrm{~Hz}$ in $8 \mathrm{mM}$ $\left[\mathrm{Ca}^{2+}\right]_{0}$ but force is the same as force in 2 $\mathrm{mM}\left[\mathrm{Ca}^{2+}\right]_{0}$ at $0.33 \mathrm{~Hz}$. spatial uniformity of the slower $\mathrm{Ca}^{2+}$ transient even during the upstroke. A similar situation should arise in myopathic human myocardium in which the $\mathrm{Ca}^{2+}$ transient and tension are of even longer duration. We calculated resting levels of calcium for control and myopathic human muscles which were $0.225 \pm 0.052$ and $0.350 \pm 0.077 \mu \mathrm{M}$, respectively. In myopathic tissue, the second component $\left(L_{2}\right)$ maintains an elevation of intracellular calcium between 0.4 and $1 \mu \mathrm{M}(0.1-0.7 \mu \mathrm{M}$ larger than resting $\left.\left[\mathrm{Ca}^{2+}\right]_{i}\right)$ and occurs at the time of expected maximum negative $\mathrm{d} F / \mathrm{d} t$. The diastolic dysfunction seen in myopathic tissue stimulated even at $0.2-0.33 \mathrm{~Hz}$ could result from an increase in resting intracellular calcium and/or an altered $\left[\mathrm{Ca}^{2+}\right]_{\text {offset }}$. We propose that in myopathic human tissue initial negative $\mathrm{d} F / \mathrm{d} t$ (i.e., initial relaxation) bears a linear relationship to $L_{2}$ and further that this relationship becomes nonlinear at an altered $\left[\mathrm{Ca}^{2+}\right]_{\text {offset }}$. Of course, differences in fiber orientation and fibrosis must be taken into account when dealing with diseased myocardium.

Postextrasystolic potentiation and restitution curves. In human myocardium, restitution and postextrasystolic potentiation of contractile response are approximated by monoexponential functions. The time constants for restitution and postextrasystolic potentiation curves from control and myopathic muscles were quite similar: 4,540 and 4,300 ms, respectively, for restitution curves; and 5,400 and 5,170 ms, respectively for postextrasystolic potentiation curves. Similar time constants for restitution and postextrasystolic potentiation curves have previously been reported by Wier and Yue and their co-workers in ferret papillary muscle and in the intact ventricle $(10,25)$. Control and myopathic tissue reached similar levels of force potentiation $\left(Y^{\circ}=216\right.$ and 196, respectively) and of peak $\left[\mathrm{Ca}^{2+}\right]_{\mathrm{i}}\left(Y^{\circ}=186\right.$ and 204). These data suggest that there is a common underlying mechanism, related to sarcoplasmic reticulum calcium release, as suggested by Wier and Yue (10). This is reflected in the similar time constants of peak $\left[\mathrm{Ca}^{2+}\right]_{\mathrm{i}}(4,900 \mathrm{~ms}$ for control and $4,300 \mathrm{~ms}$ for myopathic myocardium; Figs. 2 and 3 ).

Restitution curves in control and myopathic tissue bore no relationship to the amount of calcium $\left(L_{1}\right)$ released by the sarcoplasmic reticulum. There was greater potentiation of the extrasystole in myopathic tissue $\left(Y^{\circ}=207\right)$ versus control tissue $\left(Y^{\circ}=145\right)$. There was a relationship between the second component of the calcium transient $\left(L_{2}\right)$ in myopathic tissue, and $F_{\max }$ for restitution and postextrasystolic potentiation curves. We have shown that tetrodotoxin does not affect the amplitude of $L_{2}$ in myopathic tissue (15). This suggests that sodium-calcium exchange is not the source of the calcium and raises the possibility that restitution is related to calcium supplied from some other source, such as voltage-dependent calcium channels.

Wier and Yue reported that ryanodine (which impairs sarcoplasmic reticulum function) accelerated the time course of restitution and resulted in summation of the contractile response (10). In our experiments the time constant for the restitution curve in myopathic tissue was less than the time constant for the postextrasystolic potentiation curve $(4,300 \mathrm{vs}$. $5,170 \mathrm{~ms}$, respectively). The time course of the restitution curve for $L_{2}$ was similarly brief in myopathic tissue $(2,710 \mathrm{~ms})$. These data suggest that, despite the fact that both functions fit a monoexponential curve and are possibly due to the same underlying phenomenon (e.g., sarcoplasmic reticulum calcium release), different kinetic processes are involved in myopathic tissue.

The increase in contractile force of the extrasystole could

Table V. Action Potential Parameters

\begin{tabular}{|c|c|c|c|c|c|c|c|c|c|}
\hline & \multicolumn{4}{|c|}{$0.33 \mathrm{~Hz}$} & \multicolumn{4}{|c|}{$1 \mathrm{~Hz}$} & \multirow[b]{2}{*}{ PT } \\
\hline & APA & RP & $\mathrm{APD}_{50 \%}$ & $\mathrm{APD}_{808}$ & APA & $\mathbf{R P}$ & $\mathrm{APD}_{50 \%}$ & $\mathrm{APD}_{80 \%}$ & \\
\hline & $m V$ & $-m V$ & \multicolumn{2}{|c|}{$m s$} & $m V$ & $-m V$ & \multicolumn{2}{|c|}{$m s$} & $\%$ \\
\hline Control & $120 \pm 6$ & $78 \pm 1$ & $436 \pm 19$ & $539 \pm 20$ & $116 \pm 6$ & $76 \pm 1$ & $347 \pm 21$ & $459 \pm 21$ & $200 \pm 26$ \\
\hline Myopathic & $113 \pm 4$ & $75 \pm 2$ & $507 \pm 24^{*}$ & $658 \pm 34^{*}$ & $110 \pm 8$ & $74 \pm 2$ & $344 \pm 7$ & $483 \pm 14$ & $102 \pm 13^{*}$ \\
\hline
\end{tabular}

Abbreviations: APA, action potential amplitude; RP, resting membrane potential; $\mathrm{APD}_{50 \%}$ and $\mathrm{APD}_{80 \%}$, action potential duration at $50 \%$ and $80 \%$ repolarization (ms); PT, peak tension as percent of $0.33-\mathrm{Hz}$ peak isometric force. All measurements are listed as mean \pm SE. Significance at $P \leq 0.05$ compared with control tissue value. 

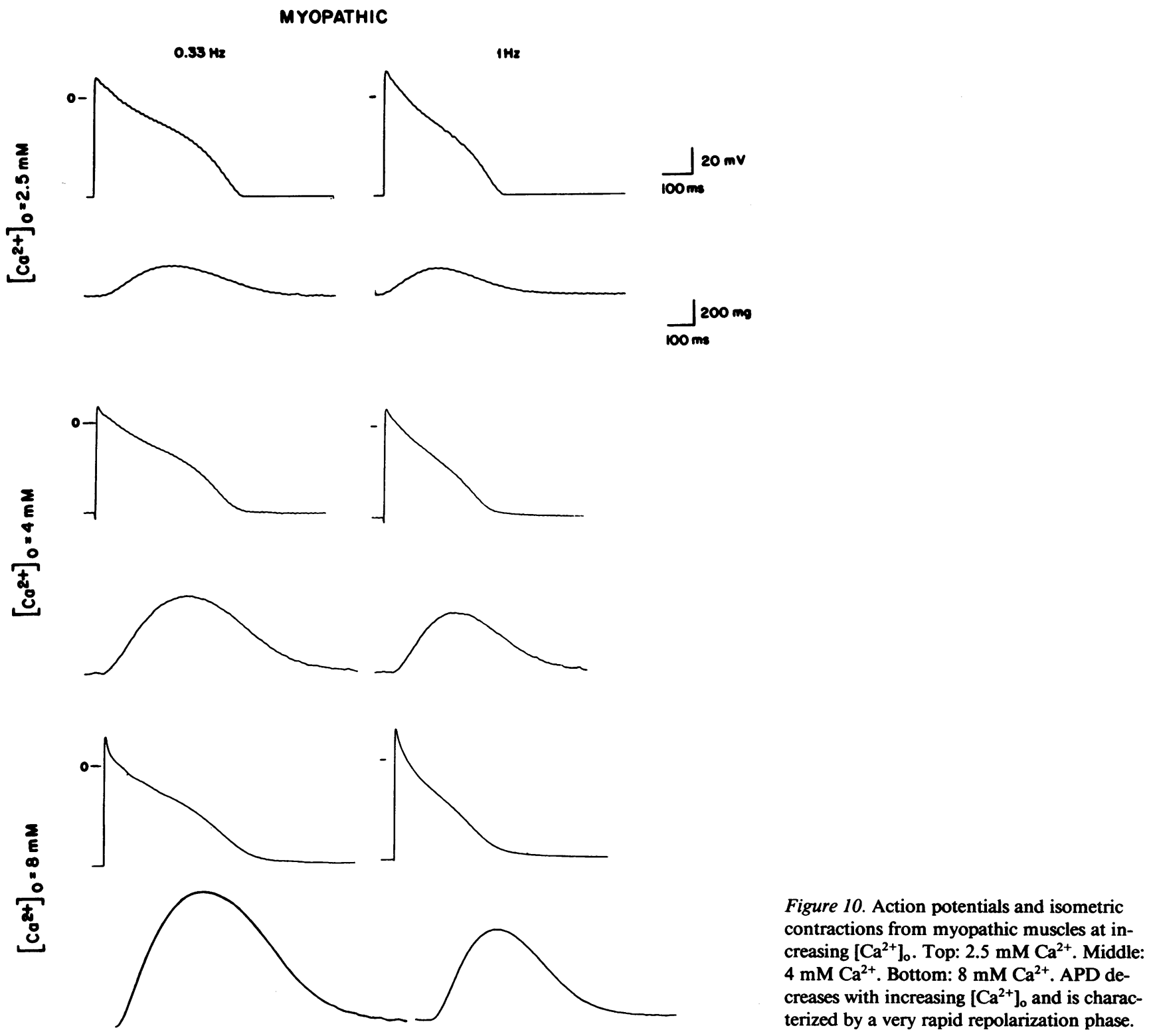
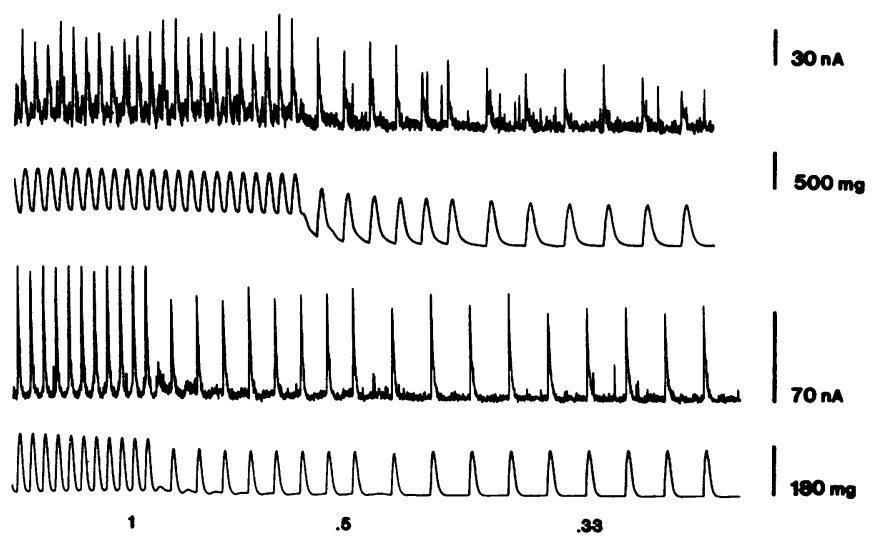

Figure 11. Calcium transients and isometric contractions from myopathic (top panels) and control (lower panels) muscles at 1-, 0.5-, and $0.33-\mathrm{Hz}$ frequencies of stimulation. Note the periodicity in the peak amplitude of the calcium transients at $1-\mathrm{Hz}$ stimulation frequency. Calcium signals were filtered at $15 \mathrm{~Hz}$. possibly be explained on the basis of frequency potentiation. The increase in contractile force of the extrasystole as a function of extrasystolic interval, however, was independent of the intracellular calcium restitution curve in control muscles. Intracellular calcium therefore did not reflect frequency potentiation. One possible explanation for the potentiation of the extrasystole is indicated by the relationship of $L_{2}$ to restitution and postextrasystolic potentiation curves in myopathic tissue. With $y$-axis offsetting, the curves are nearly superimposable except at very short intervals (Figs. 2 and 3). This suggests that in the presence of impaired sarcoplasmic reticulum calcium handling and enhanced slow inward current, calcium crossing the sarcolemma directly activates the myofilaments and results in potentiation of the extrasystole (restitution curve). This is reflected in an increased amplitude of $L_{2}$ without a corresponding increased amplitude of $L_{1}$. The postextrasystolic potentiation curve, on the other hand, is potentiated for two reasons: (a) enhanced release of calcium from the sarcoplasmic reticulum reflected in an increased amplitude of $L_{1}$ associated 


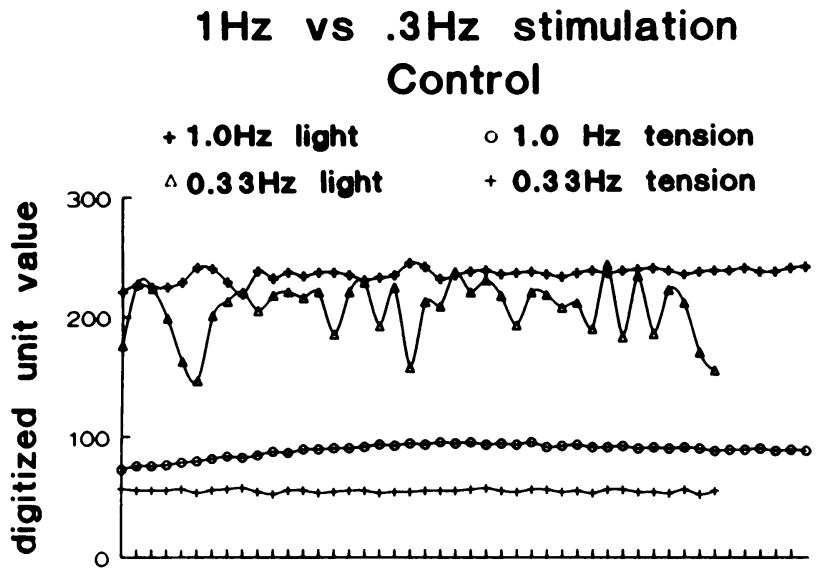

stimulus number

FFT

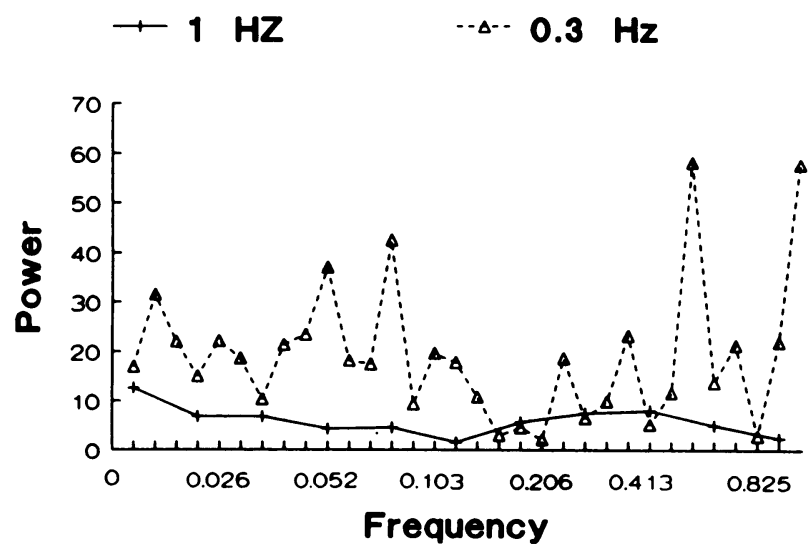

$1 \mathrm{~Hz}$ vs $.3 \mathrm{~Hz}$ stimulation
Myopathic

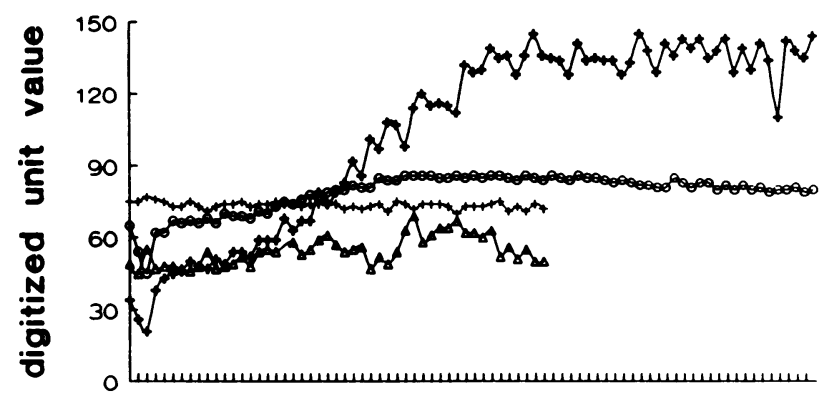

stimulus number

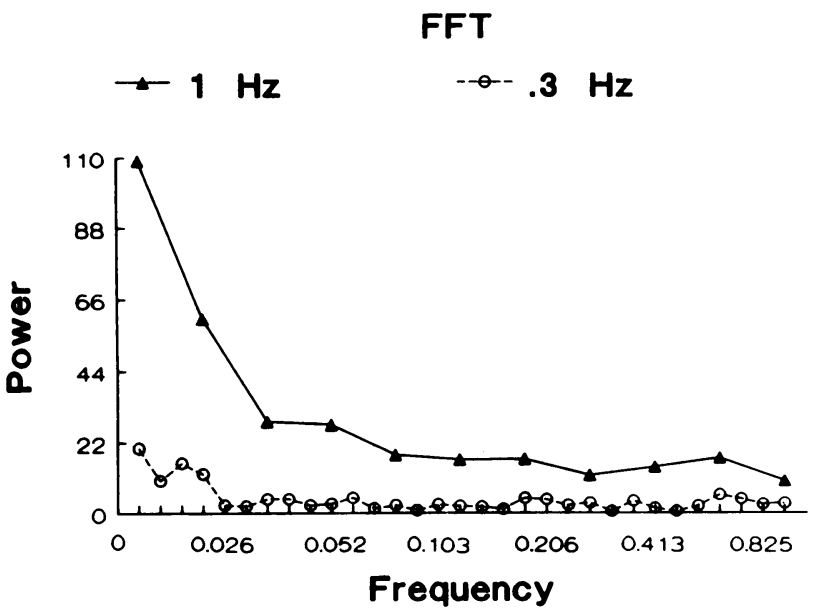

Figure 12. Peak amplitude of the calcium transient and associated isometric tension versus stimulus number. Upper panels: in control tissue the periodicity in peak calcium transient amplitude observed at $0.33-\mathrm{Hz}$ stimulation frequency is reduced as stimulation frequency is increased to $1 \mathrm{~Hz}$. There is an associated increase in isometric twitch force at the $1-\mathrm{Hz}$ stimulation frequency. Myopathic tissue demonstrates similar peak calcium transient periodicity at $0.33 \mathrm{~Hz}$ which, at $1-\mathrm{Hz}$ stimulation frequency, is increased. The large increase in amplitude of transient at $1-\mathrm{Hz}$ stimulation frequency in myopathic tissue is not associated with an increase in peak isometric force, suggesting a decreased sensitivity of the myofilaments to calcium. Lower panels: discrete Fourier transforms (FFT) of steady-state data from control (left) and myopathic tissue (right).

with the contraction and $(b)$ enhanced slow inward current reflected in an increased amplitude of $\mathrm{L}_{2}$. The lower $y$ intercept for $L_{2}$ with postextrasystolic potentiation compared to the restitution curve $\left(\mathrm{Y}^{\circ}=122\right.$ and $\mathrm{Y}^{\circ}=259$, respectively) reflects the fact that the time interval is sufficiently long to allow the homeostatic mechanisms to lower $\left[\mathrm{Ca}^{2+}\right]_{i}$ arising from enhanced influx across the sarcolemma. Since aequorin is a nonlinear calcium indicator, areas of high calcium concentration such as release sites dominate the signal. In control myocardium calcium crossing the sarcolemma binds to the myofilaments, therefore sarcoplasmic reticulum calcium release would comprise the predominant portion of the aequorin signal.

In human myocardium stimulated at a frequency of $0.2 \mathrm{~Hz}$ at $30^{\circ} \mathrm{C}$, either the translocation of calcium from uptake and release compartments is complete or the transition of channels from a closed state to an open state is complete. The shorter time constant for both calcium $\left(L_{2}\right)$ and force restitution curves in myopathic tissue suggests that the cycling time is not affected. The similarity in control and myopathic tissue of intracellular calcium release during the potentiated beat therefore reflects that, at $0.2 \mathrm{~Hz}$ frequency of stimulation, there is adequate time for calcium uptake, translocation, and release.

Changes in myocardial contractility resulting from changes in rate and rhythm of contraction may simply reflect changes in the degree of activation (i.e., the position or shape of the force-velocity curve) and/or changes in duration of the active state $(2,26,27)$. In the present study, the degree of activation, i.e., the availability of $\left[\mathrm{Ca}^{2+}\right]_{i}$, was not different between the control and myopathic tissue for either the postextrasystolic potentiation or restitution curves. The conditioned steadystate beat and postextrasystolic potentiation steady-state responses were nearly superimposable in time course. There was only slight abbreviation of the extrasystole. Our results would therefore suggest that postextrasystolic potentiation in human myocardium results from an increase in $\left[\mathrm{Ca}^{2+}\right]_{\mathrm{i}}$ availability rather than a change in the overall time course of activation.

The peak force-peak calcium relationship varied linearly 
during postextrasystolic potentiation and in the presence of increasing $\left[\mathrm{Ca}^{2+}\right]_{0}$. If prolonged calcium transients allow intracellular spatial gradients to dissipate and more truly reflect calcium availability at the level of the myofilaments $(28,29)$, then our data would suggest that there is no difference in myofilament calcium sensitivity between control and myopathic human myocardium during postextrasystolic potentiation.

Frequency potentiation. The primary differences between postextrasystolic potentiation and frequency potentiation in this study were a change in resting $\left[\mathrm{Ca}^{2+}\right]_{\mathrm{i}}$ levels, resting tension, and degree of augmentation. The increase in resting tension often occurred on the first contraction after a change in stimulation frequency. Similar findings have previously been reported in hypertrophied human myocardium $(7,30,31)$. The increase in resting intracellular calcium and tension can easily be explained on the basis of a relative calcium overload due to impaired sarcoplasmic reticulum calcium handling (7).

The upward shift in the force-frequency curve supports the hypothesis that the degree of activation of the contractile elements is altered in myopathic tissue compared to controls (Fig. 7). This is further supported by a similar upward shift in the calcium curve which reflects increased loading of the sarcoplasmic reticulum and enhanced slow inward current. Because the force-frequency curve is shifted upward for myopathic tissue, there appears to be less force when compared to control.

We found that intracellular calcium increased with increasing stimulation frequency in control and myopathic muscle. This is in agreement with other reports $(4,5,7,30)$. At the highest extracellular $\left[\mathrm{Ca}^{2+}\right](16 \mathrm{mM})$, there was no significant difference between myopathic and control muscles with respect to peak tension generated or peak intracellular calcium levels. However, at faster stimulation rates, myopathic muscles generated less isometric tension than control muscles despite a greater intracellular calcium concentration.

Regression analysis of frequency potentiation curves. Frequency potentiation curves for calcium and force were best fit by double exponential functions with an initial fast component $\left(\tau_{1}\right)$ and a slower second component $\left(\tau_{2}\right)$. This observation suggests that more than one kinetic process is involved (Fig. 7). Time constants for the initial fast components of force and calcium potentiation curves had similar relationships in control and myopathic muscles ( 2.94 vs. $2.25 \mathrm{~s}$ and 1.68 vs. $1.10 \mathrm{~s}$, respectively). This suggests a predominant contribution of sarcoplasmic reticulum calcium handling to force generation which is of similar magnitude in control and myopathic tissue. However, the somewhat faster $\tau_{1}$ in myopathic muscles suggests that another source of calcium is also involved which would most likely be from sarcolemmal calcium influx. This is corroborated by the presence of a fast $\tau_{1}(0.80 \mathrm{~s})$ for $L_{2}$ in myopathic muscle.

The slower component $\tau_{2}$, which probably reflects contributions of sarcoplasmic reticulum and sarcolemmal calcium influx to force production was much faster in the myopathic tissue for force (154 vs. $289 \mathrm{~s}$ ) and for the early calcium transient $L_{1}(185 \mathrm{vs} .475 \mathrm{~s})$. Impairment of sarcoplasmic reticulum function in myopathic tissue effectively removes a substantial calcium buffer. Therefore calcium entry across the sarcolemma would be much more effective in raising free intracellular calcium and in activating the myofilaments. The importance of transsarcolemmal calcium flux is indicated by the marked abbreviation of $\tau_{2}$. The long second time constant for
$L_{2}\left(\tau_{2}=751 \mathrm{~s}\right)$ would also suggest that sarcolemmal calcium influx plays an important role at slower frequencies of stimulation and would explain the upward shift in the force-frequency relationship at slower frequencies in myopathic tissue. The transsarcolemmal calcium influx results in enhanced sarcoplasmic reticulum calcium uptake and subsequent release. The faster $\tau_{1}$ for $L_{2}$ associated with abbreviation of $\tau_{1}$ for force in myopathic tissue suggests that $L_{2}$ plays a significant role in force potentiation at faster frequencies. The increase in amplitude of $L_{2}$ with faster rates of stimulation may arise from delayed inactivation of calcium channels resulting in increased peak sarcolemmal calcium current.

Relationship between $\left[\mathrm{Ca}^{2+}\right]_{i}$ and force-frequency potentiation. Peak isometric tension is determined by intracellular calcium availability, myofilament responsiveness to calcium, and the kinetics of cross-bridge cycling. Hypertrophied human myocardium probably has a slower cross-bridge cycling rate as has been demonstrated for other species with hypertrophy. A reduction in cross-bridge cycling rate, which increases the economy of force maintenance, would reflect an adaptation of myopathic tissue to prolongation of the intracellular calcium transient and resultant tension duration. This mechanism could explain our previous finding that similar if not greater isometric tension develops in myopathic tissue compared to control at slower frequencies of stimulation $(7,20)$.

Since isometric force development lies on the steep portion of the force-calcium relationship, minor changes in myofilament calcium sensitivity could result in significant changes in peak force (32) (see Fig. 9). $\left[\mathrm{Ca}^{2+}\right]_{\mathrm{i}}$ attained during tetanization after a $1-\mathrm{Hz}$ stimulation rate is the same $\left[\mathrm{Ca}^{2+}\right]_{i}$ at $0.33 \mathrm{~Hz}$ in the presence of $8 \mathrm{~mm}\left[\mathrm{Ca}^{2+}\right]_{0}$; however, the associated steadystate force is only equivalent to force attained in $2 \mathrm{mM}\left[\mathrm{Ca}^{2+}\right]_{0}$ at $0.33 \mathrm{~Hz}$. This clearly demonstrates a shift to the right in the force-calcium relationship, indicating a decreased responsiveness of the myofilaments to calcium. Decreased myofilament calcium sensitivity could result from the accumulation of metabolites as a result of altered mitochondrial metabolism (33) or as a result of accumulation of inorganic phosphate (34). Similarly, repletion of high-energy phosphates with reduction of intracellular inorganic phosphate would explain the force augmentation seen with posttetanization delays.

Effect of frequency on action potential parameters. We investigated the relationship between action potential duration and the effects of stimulation frequency on isometric tension. Adjustment to a new steady state action potential duration was slower in myopathic muscles than in control muscles. This difference is similar to findings in Purkinje fibers in which there is also a delayed component to the calcium transient $(9$, $35,36)$. Elevated $\left[\mathrm{Ca}^{2+}\right]_{0}$ significantly abbreviated the repolarization phase in myopathic muscles stimulated at $0.33 \mathrm{~Hz}$. This abbreviation was similar to the abbreviation seen at a $1-\mathrm{Hz}$ stimulation frequency in normal $\left[\mathrm{Ca}^{2+}\right]_{0}$ and would suggest that alterations in action potential shape and APD result from differences in the repolarization phase. The increase in resting/diastolic $\left[\mathrm{Ca}^{2+}\right]_{i}$ in myopathic tissue could result in inactivation of calcium currents and activation of calcium-dependent potassium channels to produce a shortening of APD (37). Another potential mechanism for the observed abbreviation of APD is activation of ATP-inhibited potassium currents. It has been reported that ATP-inhibited potassium channels in hypertrophied ventricular myocytes require a smaller decrease in [ATP] for release of inhibition (38). There- 
fore, a small reduction in high energy intracellular phosphate concentration such as might occur with lowered creatine kinase activity (33) could result in enhanced repolarization.

Altered sodium channel kinetics in myopathic muscles might also produce the observed alterations in APD. Agents that delay sodium channel inactivation prolong APD (15). This might in turn produce an increase in $\left[\mathrm{Ca}^{2+}\right]_{i}$, via $\left[\mathrm{Na}^{+}-\right.$ $\mathrm{Ca}^{2+}$ ] exchange. Current technology does not permit easy study of $\mathrm{Na}^{+}$channels from human myocardium but this requires further examination.

Fluctuations of sarcoplasmic reticulum calcium handling. Recent observations indicate that intracellular calcium content oscillates at the onset of increases in stimulation frequency or after long periods of inactivity $(39,40)$. At faster stimulation rates reduced and/or slower uptake of calcium by the sarcoplasmic reticulum could lead to accumulation of $\left[\mathrm{Ca}^{2+}\right]_{\mathrm{i}}$. The periodicity in the amplitude of the peak calcium transient could result from an unstable calcium release from the sarcoplasmic reticulum with resultant graded sarcoplasmic reticulum calcium release. Abbreviation of the action potential with increasing stimulation frequency would result in less calcium flux across the sarcolemma and therefore less calcium release from the sarcoplasmic reticulum. It has been reported that calcium-induced calcium release from the sarcoplasmic reticulum is rate-dependent, and that the effectiveness of the calcium release trigger can be affected by changes in intracellular ionic concentrations (41).

Changes in APD can affect the release of calcium from the sarcoplasmic reticulum thereby affecting peak force $(39,40)$. Similarly, variations in the amount of sarcoplasmic reticulum $\mathrm{Ca}^{2+}$ release affect the $\mathrm{Ca}^{2+}$ influx across the sarcolemma. Interactions of these systems each of which might proceed with different kinetics would produce a continuing variation in peak $\left[\mathrm{Ca}^{2+}\right]_{i}$. An increase in resting $\left[\mathrm{Ca}^{2+}\right]_{i}$ could further alter these relationships with resultant instability in excitation-contraction coupling (42).

Summary. In human ventricular myocardium, postextrasystolic potentiation is the result of an increased availability of activator calcium which arises predominantly from the sarcoplasmic reticulum. In myopathic human myocardium, impaired sarcoplasmic reticulum calcium handling removes a significant buffer of free ionized calcium. Therefore, calcium influx from voltage-dependent calcium channels plays a more significant role. Potentiation of the extrasystole predominantly reflects a sarcolemmal event whereas potentiation of the postextrasystolic contraction occurs as a result of enhanced $\mathrm{Ca}^{2+}$ influx and increased calcium release from the sarcoplasmic reticulum.

Frequency potentiation is the result of an increased availability of activator calcium and an abbreviation in the duration of the active state. In myopathic human myocardium the action potential becomes significantly abbreviated with increasing frequency of stimulation. This results in an unstable calcium trigger with resultant graded sarcoplasmic reticulum calcium release. The impaired uptake of calcium by the sarcoplasmic reticulum results in a rise in resting calcium and resting tension which could further abbreviate the action potential through activation of calcium-activated potassium currents and/or inactivation of slow inward calcium currents. Our data also suggest that the reduced augmentation of peak force is due to the accumulation of an intracellular metabolite such as inorganic phosphate. Interestingly breakdown of creatine phos-
phate/ATP which leads to an increase in inorganic phosphate could also activate a repolarizing potassium current. We therefore propose that alterations in the action potential, in conjunction with the accumulation of inorganic phosphate, result in impairment of force-frequency potentiation in myopathic tissue.

Altered mechanical responses in myopathic human myocardium are not due to diminished intracellular calcium availability. In fact, resting intracellular calcium concentrations are significantly higher in myopathic tissue compared to control.

Clinical implications. The results of these studies have several important clinical implications. First, because the rate-dependent dysfunction of myopathic human muscle does not appear to be caused by decreased availability of activator $\mathrm{Ca}^{2+}$, preventive and therapeutic measures should not be directed towards increasing $\left[\mathrm{Ca}^{2+}\right]_{\mathrm{i}}$ with inotropic agents such as digitalis that may create or exacerbate cellular calcium overload. Secondly, use of agents that enhance sarcoplasmic reticulum calcium resequestration and cause an amelioration of rate-related $\left[\mathrm{Ca}^{2+}\right]_{\mathrm{i}}$ handling abnormalities should have a beneficial effect in patients. Thirdly, our findings may explain the beneficial effects of slowing the heart rates in patients with significant cardiac hypertrophy and failure, since bradycardia allows sufficient time for impaired restitution processes to operate. Conversely, these results explain the rate-related decrease in compliance in the hypertrophied ventricle, and the inability of patients with congestive heart failure and compensatory hypertrophy to tolerate tachycardia.

\section{Acknowledgments}

The authors wish to express their appreciation to the New England Organ Bank. Dr. William Grossman is thanked for his scientific input into this study. We thank Drs. Paul D. Allen, James Marsh, Tomoko Ohkusa, and Frederick Schoen for their assistance in the completion of this project. The authors wish to acknowledge Neil J. Richmond, Nancy Hague, and Cynthia Perreault for technical assistance.

This work was supported in part by Dominion, Manquin, VA; a FIRST Award (HI-39091); a grant-in-aid from the Massachusetts Heart Association to J. K. Gwathmey and a Biomedical Research Award from the Beth Israel Hospital to J. K. Gwathmey and Roger Hajjar; fellowship awards from the Massachusetts Affiliate of the American Heart Association to Mara T. Slawsky and G. Maurice Briggs; HL-31117, HL-01611, and a grant-in-aid from the American Heart Association to J. P. Morgan. J. K. Gwathmey is an Established Investigator supported by the American Heart Association. Publication costs are supported in part by the Christine Anne Bohannon Endowment Fund.

\section{References}

1. Bowditch, H. P. 1871. Über die Eigenthümlichkeiten der Reizbarkeit, welche die Muskelfasem des Herzens zeigen. Ber. Sächs. Ges. (Akad.) Wiss. 652-689.

2. Koch-Weser, J., and J. R. Blinks. 1963. The influence of the interval between beats on myocardial contractility. Pharmacol. Rev. 15:601-652.

3. Orchard, C. H., and E. G. Lakatta. 1985. Intracellular calcium transients and developed tensions in rat heart muscle: a mechanism for the negative interval-strength relationship. J. Gen. Physiol. 86:637651 .

4. Buckley, N. M., Z. J. Penefsky, and R. S. Litwak. 1972. Comparative force-frequency relationships in human and other mammalian ventricular myocardium. Pflügers Arch. Gesamte Physiol. Menschen Tiere. 332:259-270. 
5. Penefsky, Z. J., N. M. Buckley, and R. S. Litwak. 1972. Effects of temperature and calcium on force-frequency relationships in mammalian ventricular myocardium. Pflügers Arch. Gesamte Physiol. Menschen Tiere. 332:271-282.

6. Grossman, W., L. P. McLaurin, and E. L. Rolett. 1979. Alteration in left ventricular relaxation and diastolic compliance in congestive cardiomyopathy. Cardiovasc. Res. 13:514-522.

7. Gwathmey, J. K., L. Copelas, R. MacKinnon, R. J. Schoen, M. D. Feldman, W. Grossman, and J. P. Morgan. 1987. Abnormal intracellular calcium handling in myocardium from patients with end-stage heart failure. Circ. Res. 61:70-76.

8. Li, Q., B. Biagi, R. Starling, C. Hohl, R. Altschuld, and B. Stokes. 1989. Characteristics of calcium transients and electrophysiology in human ventricular myocytes. Biophys. J. 55:488a. (Abstr.)

9. Wier, G. W. 1980. Calcium transients during excitation-contraction coupling in mammalian heart: aequorin signals of canine Purkinje fibers. Science (Wash. DC). 207:1085-1087.

10. Wier, W. G., and D. T. Yue. 1986. Intracellular calcium transients underlying the short-term force-interval relationship in ferret ventricular myocardium. J. Physiol. (Lond.). 376:507-530.

11. Blinks, J. R. 1966. Field stimulation as a means of effecting the graded release of autonomic transmitters in isolated heart muscle. $J$. Pharmacol. Exp. Ther. 151:221-235.

12. Gwathmey, J. K., and J. P. Morgan. 1985. Altered calcium handling in experimental pressure-overload hypertrophy in the ferret. Circ. Res. 57:836-843.

13. Allen, D. G., and J. R. Blinks. 1979. The interpretation of light signals from aequorin: injected skeletal and cardiac muscle cells: a new method of calibration. In Detection and Measurement of Free $\mathrm{Ca}^{2+}$ in Cells. C. C. Ashley and A. K. Campbell, editors. Elsevier Science Publishers, Amsterdam. 159-174.

14. Blinks, J. R. 1982. The use of photoproteins as calcium indicators in cellular physiology. In Techniques in Cellular Physiology. P. Baker, editor. Elsevier Scientific Publishers, Limerick, Ireland. 1-38.

15. Gwathmey, J. K., M. T. Slawsky, G. M. Briggs, and J. P. Morgan. 1988. Role of intracellular sodium in the regulation of intracellular calcium and contractility: effects of DPI 201-106 on excitation-contraction coupling in human ventricular myocardium. J. Clin. Invest. 82:1592-1605.

16. Draper, N. R., and H. Smith. 1981. Applied regression analysis, 2nd ed. Wiley-Interscience, New York. 94, 462-468, 472.

17. Orchard, C. H., D. A. Eisner, and D. G. Allen. 1983. Oscillations of intracellular $\mathrm{Ca}^{2+}$ in mammalian cardiac muscle. Nature (Lond.). 304:735-738.

18. Urthaler, F., A. A. Walker, D. N. S. Reeves, and L. L. Hefner. 1988. Maximal twitch tension in intact length-clamped ferret papillary muscles evoked by modified post-extrasystolic potentiation. Circ. Res. 62:65-74.

19. Koch-Weser, J. 1963. Effects of rate changes on strength and time course of contraction of papillary muscle. Am. J. Physiol. 204:451-457.

20. Feldman, M. D., L. Copelas, J. K. Gwathmey, P. Phillips, S. E. Warren, F. J. Schoen, W. Grossman, and J. P. Morgan. 1987. Deficient production of cyclic AMP: pharmacologic evidence of an important cause of contractile dysfunction in patients with end-stage heart failure. Circulation. 75:331-339.

21. Garvey, J. L., E. G. Kranias, and R. J. Solaro. 1988. Phosphorylation of C-protein, troponin I and phospholamban in isolated rabbit hearts. Biochem. J. 249:709-714.

22. Harigaya, S., and A. Schwartz. 1969. Rate of calcium binding and uptake in normal animal and failing human cardiac muscle. Circ. Res. 25:781-794.

23. Gwathmey, J. K., and R. J. Hajjar. Force-calcium relationships in human myocardium. J. Mol. Cell Cardiol. 21(Suppl. III):s.10. (Abstr.)
24. Yue, D. T. 1987. Intracellular $\left[\mathrm{Ca}^{2+}\right]$ related to rate of force development in twitch contraction of heart. Am. J. Physiol. 252:H760-H770.

25. Yue, D. T., D. Burkhoff, M. R. Franz, W. C. Hank, and K. Sagawa. 1985. Post-extrasystolic potentiation of the isolated canine left ventricle: Relationship to mechanical restitution. Circ. Res. 56:340350.

26. Blinks, J. R., and J. Koch-Weser. 1961. Analysis of the effects of change in rate and rhythm upon myocardial contractility. J. Pharmacol. Exp. Ther. 134:373-389.

27. Hoffman, B. F., E. Bindler, and E. E. Suckling. 1956. Post-extrasystolic potentiation of contraction in cardiac muscle. Am. J. Physiol. 185:95-102.

28. Yue, D. T., E. Marban, and W. G. Wier. 1986. Relationship between force and intracellular calcium in tetanized mammalian heart muscle. J. Gen. Physiol. 87:223-242.

29. Gwathmey, J. K., and R. J. Hajjar. 1988. Steady-state tension$\left[\mathrm{Ca}^{2+}\right]$ relationship in intact human myocardium. Biophys. J. 53:437a. (Abstr.)

30. Gwathmey, J. K., M. D. Feldman, S. E. Warren, W. Grossman, and J. P. Morgan. 1986. Increased diastolic tone in myopathic human heart muscle. Circulation. 74(Suppl. II):290. (Abstr.)

31. Feldman, M. D., J. K. Gwathmey, P. Phillips, F. Schoen, and J. P. Morgan. 1988. Reversal of the force-frequency relationship in working myocardium from patients with end-stage heart failure. $J$. Appl. Cardiol. 3:273-283.

32. Hajjar, R. J., and J. K. Gwathmey. 1988. Calcium-activation in control and myopathic human myocardium. Circulation. 78:II-265. (Abstr.)

33. Ingwall, J. S., M. F. Kramer, M. A. Fifer, B. H. Lorell, R. Shemin, W. Grossman, and P. D. Allen. 1985. The creatine kinase system in normal and diseased human myocardium. N. Engl. J. Med. 313:1050-1054.

34. Herzig, J. W., J. W. Peterson, J. C. Ruegg, and R. J. Solaro. 1981. Vanadate and phosphate ions reduce tension and increase cross-bridge kinetics in chemically skinned heart muscle. Biochim. Biophys. Acta. 672:191-196.

35. Hauswirth, O., D. Noble, and R. W. Tsien. 1972. The dependence of plateau currents in cardiac Purkinje fibers on the interval between action potentials. J. Physiol. (Lond.). 222:27-49.

36. Saitoh, H., J. G. Bailey, and B. Surawicz. 1988. Alternans of action potential duration after abrupt shortening of cycle length: differences between dog Purkinje and ventricular muscle fibers. Circ. Res. 62:1027-1040.

37. Lee, K. S., E. Marban, and R. W. Tsien. 1985. Inactivation of calcium channels in mammalian heart cells: joint dependence on membrane potential and intracellular calcium. J. Physiol. (Lond.). 364:395-411.

38. Cameron, J. S., S. Kimura, D. A. Jackson-Burns, D. B. Smith, and A. L. Bassett. 1988. ATP-sensitive $\mathrm{K}^{+}$channels are altered in hypertrophied ventricular myocytes. Am. J. Physiol. 255:H12541258.

39. Kort, A. A., and E. G. Lakatta. 1988. Spontaneous sarcoplasmic reticulum calcium release in rat and rabbit cardiac muscle: relation to transient and rest-state twitch tension. Circ. Res. 63:969-979.

40. Kort, A. A., and E. G. Lakatta. 1988. Bimodal effects of stimulation on light fluctuation transients monitoring spontaneous sarcoplasmic reticulum calcium release in rat cardiac muscle. Circ. Res. 63:960-968.

41. Fabiato, A., and F. Fabiato. 1978. Effects of pH on the myofilaments and the sarcoplasmic reticulum of skinned cells from cardiac and skeletal muscles. J. Physiol. (Lond.). 276:233-255.

42. Wier, W. G., A. A. Kort, M. P. Stern, E. G. Lakatta, and E. Marban. 1983. Cellular calcium fluctuations in mammalian heart, direct evidence from noise analysis of aequorin signals in Purkinje fibers. Proc. Natl. Acad. Sci. USA. 80:7367-7371. 